\title{
Impacts of Radiation and Cold Pools on the Intensity and Vortex Tilt of Weak Tropical Cyclones Interacting with Vertical Wind Shear
}

\author{
ROSIMAR RIOS-BERRIOS \\ National Center for Atmospheric Research, Boulder, Colorado
}

(Manuscript received 7 June 2019, in final form 14 November 2019)

\begin{abstract}
Idealized numerical simulations of weak tropical cyclones (e.g., tropical depressions and tropical storms) in sheared environments indicate that vortex tilt reduction and convective symmetrization are key structural changes that can precede intensification. Through a series of ensembles of idealized numerical simulations, this study demonstrates that including radiation in the simulations affects the timing and variability of those structural changes. The underlying reason for those effects is a background thermodynamic profile with reduced energy available to fuel strong downdrafts; such a profile leads to weaker lower-tropospheric ventilation, greater azimuthal coverage of clouds and precipitation, and smaller vortex tilt with radiation. Consequently, the simulations with radiation allow for earlier intensification at stronger shear magnitudes than without radiation. An unexpected finding from this work is a reduction of both vortex tilt and intensity variability with radiation in environments with $5 \mathrm{~m} \mathrm{~s}^{-1}$ deep-layer shear. This reduction stems from reduced variability in nonlinear feedbacks between lower-tropospheric ventilation, cold pools, convection, and vortex tilt. Sensitivity experiments confirm the relationship between those processes and suggest that microphysical processes (e.g., rain evaporation) are major sources of uncertainty in the representation of weak, sheared tropical cyclones in numerical weather prediction models.
\end{abstract}

\section{Introduction}

The complex interaction of tropical cyclones with environmental vertical wind shear involves both dynamic and thermodynamic processes. Differential vorticity advection by the sheared flow tilts the vortex from its vertical axis of rotation. At the same time, stormrelative flow associated with shear can mix cool, dry air from the environment with warm, moist air within the tropical cyclone-a process known as ventilation (Frank and Ritchie 2001; Kwon and Frank 2008; Tang and Emanuel 2010; Riemer et al. 2010; Riemer and Laliberté 2015). These dynamic and thermodynamic processes are strongly coupled (Riemer et al. 2010; Riemer and Montgomery 2011; Rios-Berrios et al. 2018); however, the effects of ventilation on vortex tilt, especially of weak tropical cyclones, are relatively unexplored. Another unexplored topic is the effect of radiation on structural changes relevant to the outcome of tropical cyclone-shear interactions (i.e., weakening or intensification). That outcome strongly depends on environmental thermodynamics (Tao and Zhang 2014; Rios-Berrios et al. 2016b,a; Munsell

Corresponding author: Rosimar Rios-Berrios, rberrios@ucar.edu et al. 2017; Rios-Berrios and Torn 2017; Nguyen et al. 2017) and on the ability of a sheared tropical cyclone vortex to reduce its tilt (Rios-Berrios et al. 2018, and references therein). The present study analyzes the effects of radiation, while also investigating the role of thermodynamic processes, on simulated vortex tilt and intensity changes of weak tropical cyclones in sheared environments.

Weak tropical cyclones-tropical depressions, tropical storms, and low-end hurricanes-are structurally different than strong hurricanes. Those weak systems are characterized by disorganized and buoyant convection, relatively shallow azimuthal circulations, and weak radial gradients of near-surface equivalent potential temperature (McBride and Zehr 1981; Frank 1982; Molinari et al. 2004; Dolling and Barnes 2012; Nugent and Rios-Berrios 2018). Their surface centers of circulation can be difficult to identify by aircraft or satellite images. Strong hurricanes, in contrast, exhibit welldefined eyewalls surrounded by rainbands, strong and deep azimuthal circulations, and pronounced radial gradients of near-surface equivalent potential temperature (e.g., Frank 1984; Houze 2010; Rogers et al. 2012). Whether those structural differences affect 
dynamic and thermodynamic processes during tropical cyclone-shear interactions is unclear because most studies on these issues assume the presence of a strong, deep, and symmetric vortex-something more representative of major hurricanes than of weak tropical cyclones. This issue must be clarified because some of the most uncertain track, intensity, and rainfall forecasts happen with weak tropical cyclones in sheared environments (e.g., Nguyen and Molinari 2012; Molinari et al. 2004; Rios-Berrios et al. 2016a,b; Nugent and RiosBerrios 2018; Ryglicki et al. 2018).

Weak tropical cyclones are difficult to sample because they mostly happen far from in situ observing platforms. That challenge has been alleviated in recent years through idealized numerical simulations, which typically use a full-physics model to solve for the evolution of a tropical cyclone-like vortex in a prescribed environment. Although not entirely realistic, idealized numerical simulations serve as controlled laboratories where one can examine the role of factors (e.g., environmental humidity) and processes (e.g., ventilation) on multiple aspects of tropical cyclones. This benefit has led to the discovery that tropical cyclone-vertical wind shear interactions are sensitive to both large-scale and convective-scale factors. In particular, the simulated intensity is affected by the relative orientation between shear and tropical cyclone motion (Rappin and Nolan 2012; Onderlinde and Nolan 2016), the amount and relative location of dry air with respect to shear direction (Ge et al. 2013; Tao and Zhang 2014), the underlying sea surface temperature (Nolan and Rappin 2008; Tao and Zhang 2014), the shape of the environmental wind profile (Onderlinde and Nolan 2014; Finocchio et al. 2016; Ryglicki et al. 2018), and the boundary layer water vapor (Zhang and Tao 2013; Rios-Berrios et al. 2018).

Regardless of parameters studied, the underlying cause for the sensitivity in idealized simulations is typically the magnitude of vortex tilt and the timing of vortex realignment. Generally, the simulations show that an initially weak vortex tilts downshear while developing a convective asymmetry. A midtropospheric vortex, smaller in scale than the main tropical cyclone, emerges within the shear-organized convection (Rios-Berrios et al. 2018). If the midtropospheric vortex is not continuously advected away from the surface center, the midtropospheric vortex and its associated convection migrate azimuthally around the surface center at a speed and distance that are modulated by the factors mentioned in the previous paragraph. The underlying processes governing the timing of such azimuthal migration are unclear. Vortex tilt reduction, convective symmetrization, and reduced boundary layer ventilation-key structural changes preceding intensification (Miyamoto and Nolan
2018; Rios-Berrios et al. 2018)—follow quickly after the midtropospheric vortex enters the upshear-left quadrant with respect to the surface circulation center.

While idealized simulations have expanded our knowledge about intensity changes and vortex tilt in sheared environments, most studies have neglected an important process: radiation. Including radiation in idealized simulations complicates their interpretation because the background thermodynamics change in response to both solar and terrestrial radiation. Radiative processes, however, influence many aspects of tropical cyclones-from their genesis (e.g., Melhauser and Zhang 2014; Nicholls 2015; Wing et al. 2016) to their tracks (e.g., Fovell et al. 2010, 2016) to their mature structure (e.g., Bu et al. 2014; Dunion et al. 2014). Nighttime cooling, for example, destabilizes the background temperature profile above the planetary boundary layer, thus promoting sustained convection that is necessary for tropical cyclogenesis (Melhauser and Zhang 2014). Cloud-radiative feedbacks, or the interaction between hydrometeors and radiation, also promote slow, sustained ascent that moistens and expands the outer core region of tropical cyclones (Fovell et al. 2016). The simulated azimuthal migration of the midtropospheric vortex of weak tropical cyclones takes several days (e.g., Rios-Berrios et al. 2018, their Fig. 3) and is sensitive to the background thermodynamics (Tao and Zhang 2014); therefore, radiative warming and cooling at different locations during day or night, as well as their interactions with the asymmetric clouds, could also influence vortex tilt evolution (see, e.g., Fig. 7 of Melhauser and Zhang 2014) via modulations of the convection that accompanies the tilted vortex.

This study continues to exploit idealized modeling simulations to expand our knowledge of weak tropical cyclones interacting with sheared flow. The specific objectives are

- to document the effects of radiation on structural changes in idealized tropical cyclone simulations with vertical wind shear,

- to further elucidate the processes driving those structural changes, with an emphasis on vortex tilt and ventilation with and without radiation, and

- to expose the variability of those structural changes and intensity changes to thermodynamic processes.

These objectives are tackled with several 20-member ensembles of idealized simulations described in section 2. Results from those simulations, discussed in sections 3 and 4 , show that radiation impacts the intensity, structure, evolution, and variability of simulated tropical cyclones without suppressing key structural changes preceding intensification. The underlying cause of those impacts, 

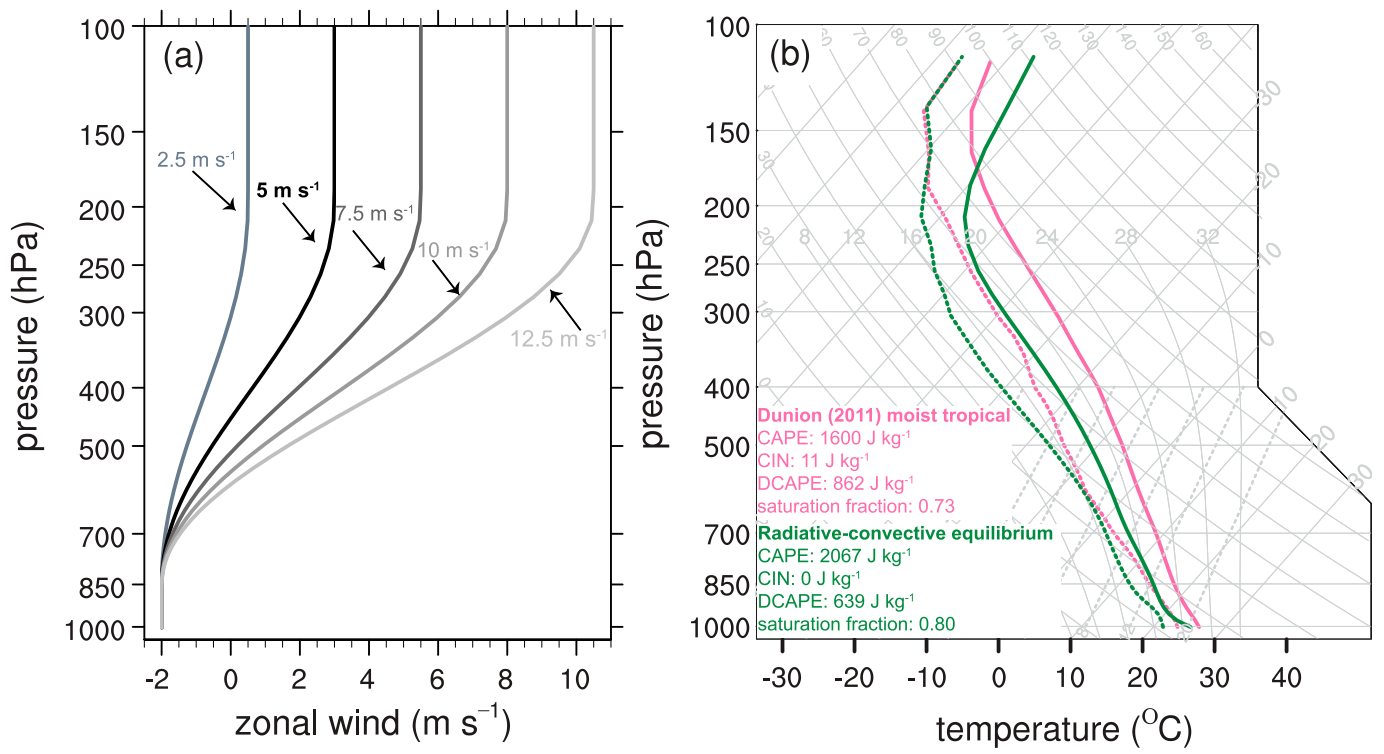

FIG. 1. (a) Vertical profiles of zonal environmental winds for the various shear magnitudes used in this study. Numbers indicate the approximate 200-850-hPa shear magnitude. (b) Skew $T$ diagram for the moist neutral sounding from Dunion (2011) (pink) and for a sounding in radiative-convective equilibrium (green). Inner box shows various metrics for each sounding.

explored in section 5, stems from reduced lowertropospheric ventilation, weaker cold pools, and earlier, less variable vortex tilt reduction with radiation. Implications of those results are discussed in section 6 .

\section{Experimental setup}

Tropical cyclone interactions with vertical wind shear were simulated with the Weather Research and Forecasting (WRF; Skamarock et al. 2008) Model, version 3.4.1. A weak, warm-core vortex was specified in the initial conditions with a modified Rankine vortex profile having maximum tangential wind of $15 \mathrm{~m} \mathrm{~s}^{-1}$ at $1.5-\mathrm{km}$ height and 135-km radius. Frank and Ritchie (1999) prescribed a similar vortex in their simulations to mimic observations of weak tropical cyclones by McBride and Zehr (1981). Because a surface circulation exists in the initial conditions, the simulations are adequate to examine the weak stage of tropical cyclones after cyclogenesis. Tangential winds vanish at a $600-\mathrm{km}$ radius and decay vertically following an exponential function [Moon and Nolan 2010, their Eq. (8)].

Around the tropical cyclone-like vortex, environmental winds were specified with entirely zonal wind profiles. Figure 1a shows the profiles, where all profiles contain $2 \mathrm{~m} \mathrm{~s}^{-1}$ easterly winds at and below $850 \mathrm{hPa}$ increasing in magnitude aloft following a cosine of log pressure to yield westerly shear magnitudes of $2.5,5,7.5,10$, and $12.5 \mathrm{~m} \mathrm{~s}^{-1}$. Most of the experiments discussed here used the $5 \mathrm{~m} \mathrm{~s}^{-1}$ westerly shear profile. Environmental winds were held constant throughout the simulations using the method of Nolan (2011), commonly referred to as the "point downscaling" method. In short, the profile remains constant by adding an acceleration term to the momentum equations in lieu of the small temperature gradient necessary for keeping the environment in thermal wind balance. For more information about the method, including its benefits and drawbacks, see Nolan (2011).

Three two-way nested domains were used with 18-, $6-$, and $2-\mathrm{km}$ grid spacing. The domains contained $240 \times 240,240 \times 240$, and $360 \times 360$ grid points, respectively. All domains had 40 vertical levels with a model top around $56 \mathrm{hPa}$, constant sea surface temperature (SST) of $27^{\circ} \mathrm{C}$, and constant planetary vorticity (i.e., $f$ plane) corresponding to $20^{\circ} \mathrm{N}$. The two innermost domains followed the simulated tropical cyclone and used "convection permitting" resolution; therefore, no cumulus parameterization was used in any domain. Other subgrid-scale processes were parameterized with the WSM6 microphysics (Hong et al. 2004), the YSU planetary boundary layer (Hong et al. 2006), and the similarity theory surfacelayer schemes (Skamarock et al. 2008). This configuration and choice of physics packages are nearly identical to most studies that used WRF to explore the sensitivity of intensity changes in sheared environments to large-scale and convective-scale factors (cf. section 1). 
A noteworthy difference from previous idealized modeling studies is the comparison of simulations with and without radiation. To this end, two sets of experiments were extensively analyzed. The first set, referred to as CTL5 hereafter, used the moist tropical sounding of Dunion (2011), $5 \mathrm{~m} \mathrm{~s}^{-1}$ westerly shear, and no radiation. This set was extensively analyzed by Rios-Berrios et al. (2018). The second set, referred to as RAD5, is similar to CTL5 except with radiation using the Rapid Radiative Transfer Model for GCMs (RRTMG) parameterization scheme (Iacono et al. 2008) for both longwave and shortwave radiation with a 10-min time step. Perpetual equinoctial conditions were prescribed by fixing the declination angle at $0^{\circ}$ and the solar constant at $1370 \mathrm{~W} \mathrm{~m}^{-2}$. Although the integration period spans 8 days, a perpetual equinox ensured that the simulations were not sensitive to the date specified in the initial conditions. The initial time was set to 0000 UTC at $60^{\circ} \mathrm{W}$, which means that simulations were initialized at night.

Both CTL5 and RAD5 contained 20 members to examine tropical cyclone intensity and vortex tilt variability, as well as to assess the robustness of each modeling configuration. Ensemble members were generated by perturbing the initial water vapor mixing ratio below $950 \mathrm{hPa}$ with small, uncorrelated perturbations between -0.5 and $0.5 \mathrm{~g} \mathrm{~kg}^{-1}$ sampled from a uniform distribution (Van Sang et al. 2008; Zhang and Tao 2013). This method mimics initially small errors that can grow upscale due to the chaotic nature of moist convective processes. Each ensemble contained an unperturbed member and 19 perturbed members. Additional sensitivity experiments were produced to test hypotheses stemming from CTL5 and RAD5. Details of those experiments will be provided when the experiments are motivated and analyzed.

\section{Impacts of radiation}

Radiation has profound impacts on the evolution of the simulated tropical cyclone. Those impacts are evident in time series of 10-m maximum wind speed for the CTL5 and RAD5 ensembles (Fig. 2a). The simulated tropical cyclone undergoes a gradual intensification during the first $48 \mathrm{~h}$ with or without radiation; however, substantial differences appear afterward. Without radiation, CTL5 members exhibit a period of steady-state intensity beginning around $48 \mathrm{~h}$ and ending with the onset of intensification at varying times between 97 and $132 \mathrm{~h}$. All members remain in a steady state near their peak intensity by $192 \mathrm{~h}$. In contrast, all RAD5 members depict similar intensity evolutions with small variability

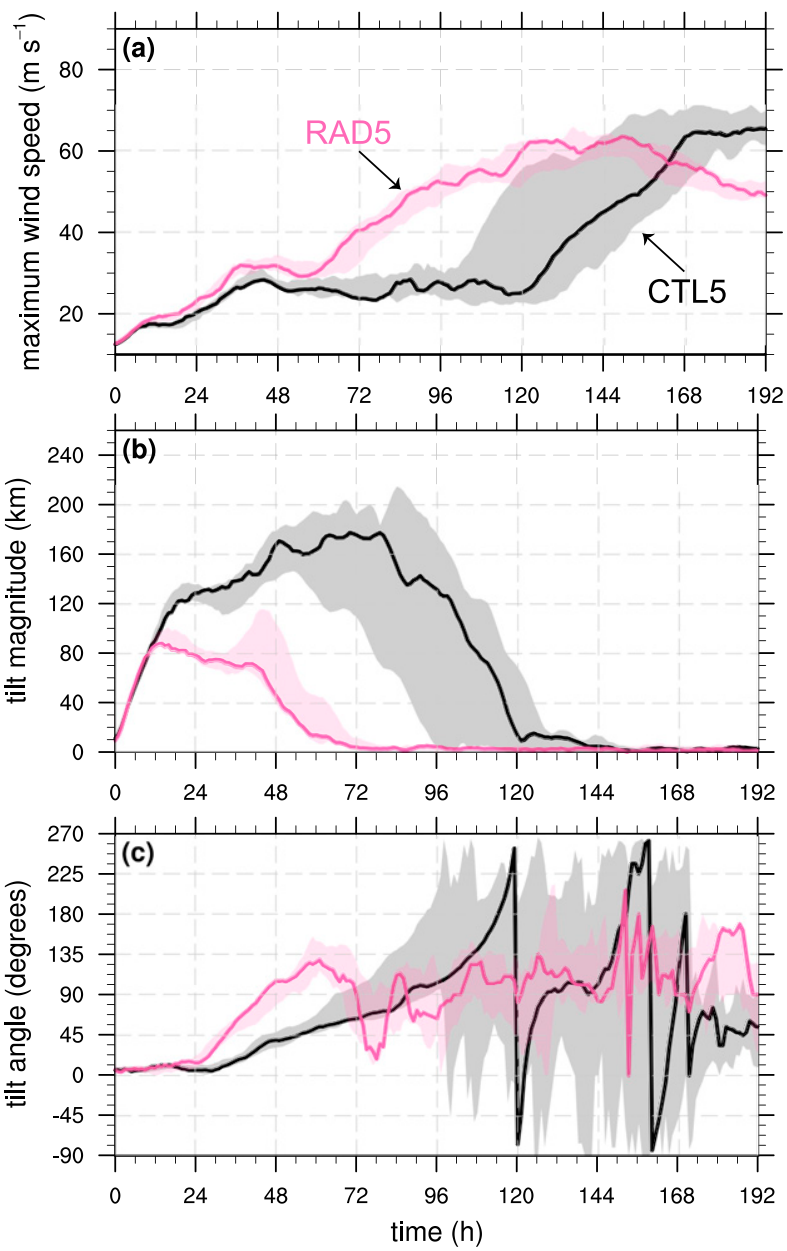

FIG. 2. Time series of hourly (a) 10-m maximum wind speed, (b) 400-900-hPa tilt magnitude, and (c) 400-900-hPa tilt angle from CTL5 (black and gray) and RAD5 (pink). Lines represent the unperturbed member from each ensemble; shading extends from ensemble-minimum to ensemble-maximum at each hour. A 6-h running mean was applied to each time series.

among members: the simulated tropical cyclone remains nearly steady state after the initial spinup, rapidly intensifies during $60-120 \mathrm{~h}$, reaches peak intensity between 120 and $144 \mathrm{~h}$, and slowly decays after $144 \mathrm{~h}$. All RAD5 members intensify at least $36 \mathrm{~h}$ earlier than their counterparts in the CTL5 ensemble, and their largest intensification rates (up to $28 \mathrm{~m} \mathrm{~s}^{-1}$ in $54 \mathrm{~h}$ ) are less pronounced than without radiation (up to $46 \mathrm{~m} \mathrm{~s}^{-1}$ in $60 \mathrm{~h}$ ).

To understand the different intensity evolutions, previously documented structural changes preceding intensification-vortex tilt reduction and convective symmetrization-were compared across experiments. Metrics commonly used to diagnose vortex tilt and convective structure guided the comparison: tilt magnitude (Fig. 2b) and tilt angle (Fig. 2c) between 

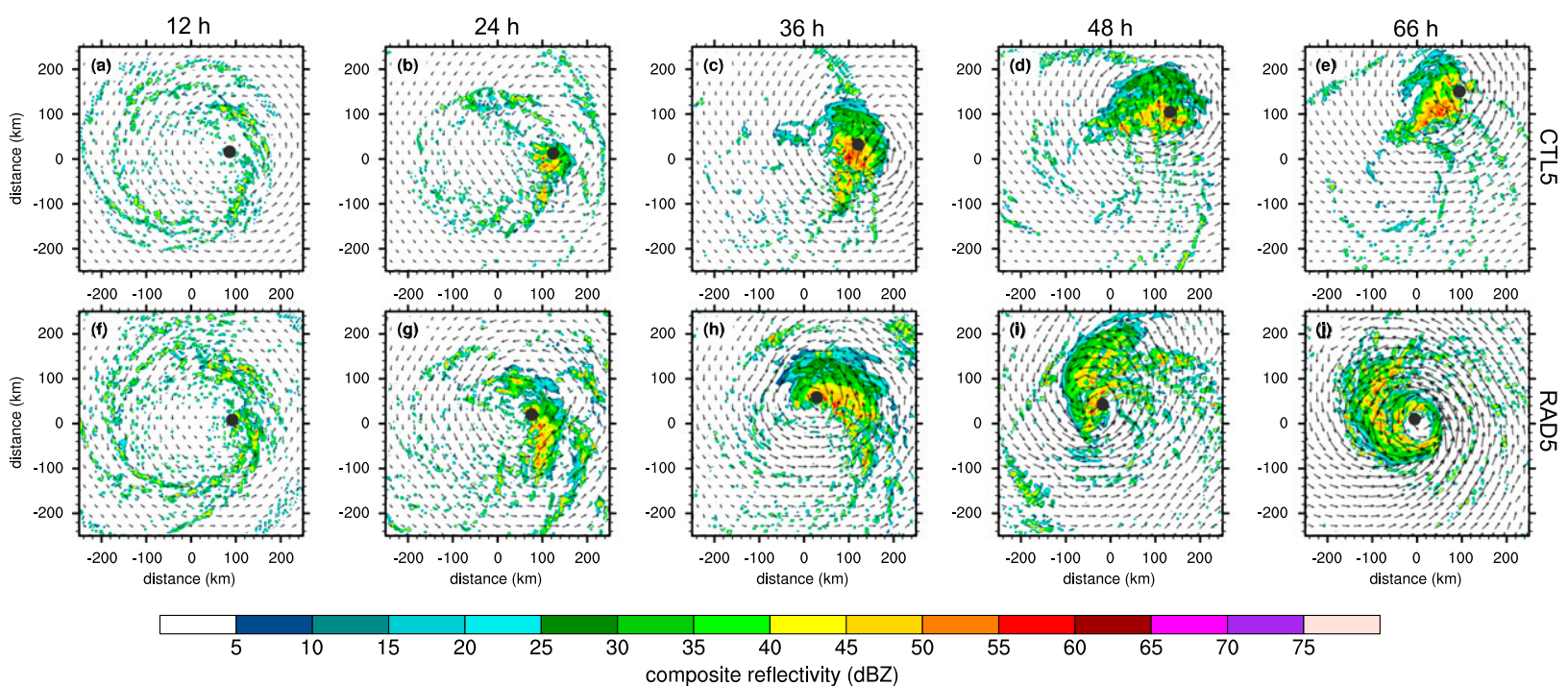

FIG. 3. Horizontal maps of composite reflectivity of the lowest $1.5 \mathrm{~km}$ (shading, every $5 \mathrm{dBZ}$ ) and 400 -hPa horizontal winds (vectors) centered on the 900-hPa center of the unperturbed member from (a)-(e) CTL5 and (f)-(j) RAD5. Columns depict the same simulation time in each experiment as specified by the labels. Dots show the 400-hPa center location.

the lower- and midtropospheric centers of circulation ${ }^{1}$ (taken here as 900 and $400 \mathrm{hPa}$, respectively), and horizontal maps of composite reflectivity and 400-hPa winds (Fig. 3). Maps will only be shown for the unperturbed members from each ensemble, which are representative of all members. Physical processes will be explored in more detail in sections 4 and 5.

A comparison of those metrics confirmed that the experiment with radiation exhibits the documented structural changes preceding intensification, albeit with important differences from the scenario without radiation. Both CTL5 and RAD5 initially develop a ring of precipitation near the radius of maximum winds $(135 \mathrm{~km})$ within the first $12 \mathrm{~h}$ (Figs. 3a,f). A displaced center of circulation is evident already at $400 \mathrm{hPa}$ and other levels where the environmental winds transition from easterlies to westerlies (cf. Fig. 1a). Tilt magnitudes quickly increase over that period while the vortex tilts toward the downshear half (Figs. 2b,c). Substantial differences between CTL5 and RAD5 emerge early in the simulations. Although both members exhibit asymmetric precipitation associated with a displaced midtropospheric vortex by $24 \mathrm{~h}$ (Figs. $3 \mathrm{~b}, \mathrm{~g}$ ), those features appear radially closer to the lower-tropospheric center with than without radiation. All RAD5 members have

\footnotetext{
${ }^{1}$ Centers of circulation were identified using the object-following method of Rios-Berrios et al. (2018), except using geopotential height instead of vorticity. The surface circulation was tracked at $900 \mathrm{hPa}$, whereas the midtropospheric circulation was tracked at $400 \mathrm{hPa}$ because the vorticity anomaly associated with the asymmetric precipitation maximized at that level.
}

400-900-hPa tilt magnitudes smaller than $90 \mathrm{~km}$ - that is, two-thirds of the tilt magnitudes from CTL5 membersby $24 \mathrm{~h}$ (Fig. 2b).

Examining the location of the 400- and 900-hPa centers in a common framework shows that such different tilt magnitudes are associated with a reduction in forward speed of the lower-tropospheric vortex of RAD5 (Figs. 4a,b). The 900-hPa center of CTL5 has moved over $100 \mathrm{~km}$ away from the initial location during the first $24 \mathrm{~h}$, while the $900-\mathrm{hPa}$ center of RAD5 has moved approximately $100 \mathrm{~km}$ during the same period. Both experiments exhibit a displaced $400-\mathrm{hPa}$ center to the north or left of the shear vector.

Structural differences amplify with time, leading to an earlier transition from an asymmetric, tilted structure to a nearly symmetric, aligned structure with than without radiation. Both CTL5 and RAD5 depict a migration of precipitation and the tilted vortex from downshear, to downshear left, and finally to upshear left (Figs. 3c-e,h,i). That migration, however, happens much faster in RAD5 than in CTL5 as demonstrated by the 400-900-hPa tilt angle (Fig. 2c) and the locations of the 400-hPa centers (Figs. 4a,b). While all RAD5 members depict a tilt angle of $90^{\circ}$ (corresponding to left of shear) between 42 and $54 \mathrm{~h}$, CTL5 members depict that tilt angle much later (around 66-90 h).

Consequently, the asymmetric precipitation and midtropospheric vortex enter upshear left at least $24 \mathrm{~h}$ earlier in the experiments with than without radiation (Fig. 3i). The differences are quite stark at $66 \mathrm{~h}$ : while RAD5 exhibits a well-defined eyewall surrounded by an asymmetric rainband (Fig. 3j), CTL5 still exhibits a largely 

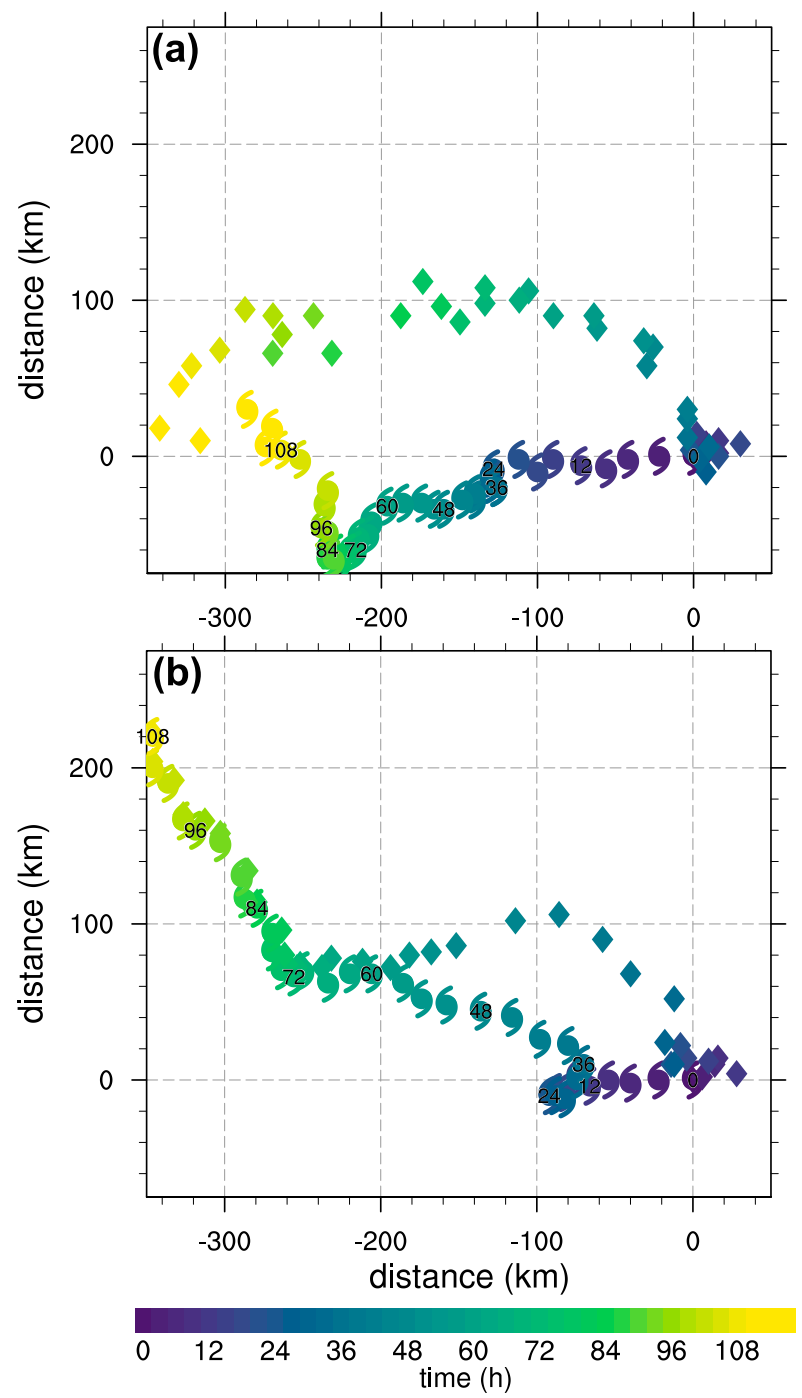

FIG. 4. The 3-hourly location of the 900-hPa (hurricane symbols) and $400-\mathrm{hPa}$ (diamonds) centers of circulation from the unperturbed member from (a) CTL5 and (b) RAD5. Color shading represents simulation time. The origin $(x=0, y=0)$ represents the location of the tropical cyclone vortex at $0 \mathrm{~h}$.

tilted vortex with asymmetric precipitation mostly in the downshear-left quadrant (Fig. 3e). The 400-900-hPa tilt magnitude quickly decreases from its maximum in both experiments (Fig. 2b) while precipitation becomes nearly symmetric. Intriguingly, tilt reduction in RAD5 is associated with an earlier migration of the lower-tropospheric vortex toward the midtropospheric vortex in comparison to CTL5 (Figs. 4a,b). These differences will be explained in section 5 .

An intriguing result from these experiments is that radiation also impacts the variability of intensity changes within the ensemble. Figure 5a quantifies those impacts through a comparison of the onset of intensification from CTL5 and RAD5. The onset of intensification was defined similarly to Rios-Berrios et al. (2018), except the threshold for intensification was defined as the 80th percentile of 24-h intensification rates (disregarding the initial 24-h spinup) for each ensemble. Here, the onset happened at the first time when the intensity change over the following 24-h met the threshold for each ensemble $\left(16.8 \mathrm{~m} \mathrm{~s}^{-1}\right.$ for CTL5 and $11.5 \mathrm{~m} \mathrm{~s}^{-1}$ for RAD5) and the intensity change over the following 6-h also met a quarter of each threshold. Without radiation, the onset of intensification happened between 97 and $132 \mathrm{~h}$. In contrast, the onset of intensification happened between 52 and $66 \mathrm{~h}$ in RAD5. Comparing the interquartile ranges confirms the statistical robustness of these results: the onset of intensification happens with less variability with than without radiation.

Intensity change variability in these idealized simulations is closely related to tilt magnitude variability resulting from the stochastic effects of boundary layer water vapor perturbations (Rios-Berrios et al. 2018, their Figs. 3b,c). Consistent with that relationship and with the smaller intensity variability, RAD5 also exhibits less vortex tilt variability than CTL5 (Fig. 5b). CTL5 members are characterized by maximum tilt magnitudes between 150 and $215 \mathrm{~km}$, whereas RAD5 members exhibit tilt magnitudes between 90 and $116 \mathrm{~km}$. However, there may be an outlier in RAD5 because the interquartile range of RAD5 extends between 93.5 and $97.3 \mathrm{~km}$, which is more than 5 times smaller than the interquartile range of CTL5. These results confirm the strong relationship between intensity and vortex tilt variability in idealized simulations.

These results could be affected by the microphysics scheme and its interactions with radiation (Fovell et al. 2016). To test that possibility, three five-member ensembles were produced with different microphysics schemes leaving all other configurations the same as in CTL5 or RAD5. Three schemes were tested: 1) Kessler (Kessler 1969), which is a warm-rain only scheme; 2) WDM6 (Lim and Hong 2010), which is a double moment scheme that is similar in formulation to WSM6; and 3) Thompson (Thompson et al. 2008), which is a partially double-moment scheme with superior skill in presenting drop size distributions of tropical cyclones (Brown et al. 2016). Time series of maximum 10-m wind speed (Figs. 6a,c,e) and 400900-hPa tilt metrics (Figs. 6b,d,f) confirm the robustness of a key result from this study: including radiation impacts the timing of tilt reduction and intensification in idealized tropical cyclone simulations with shear. All experiments with radiation exhibit earlier and less variable intensification-associated with smaller, less variable tilt magnitudes and earlier tilt reductions- than without radiation. 

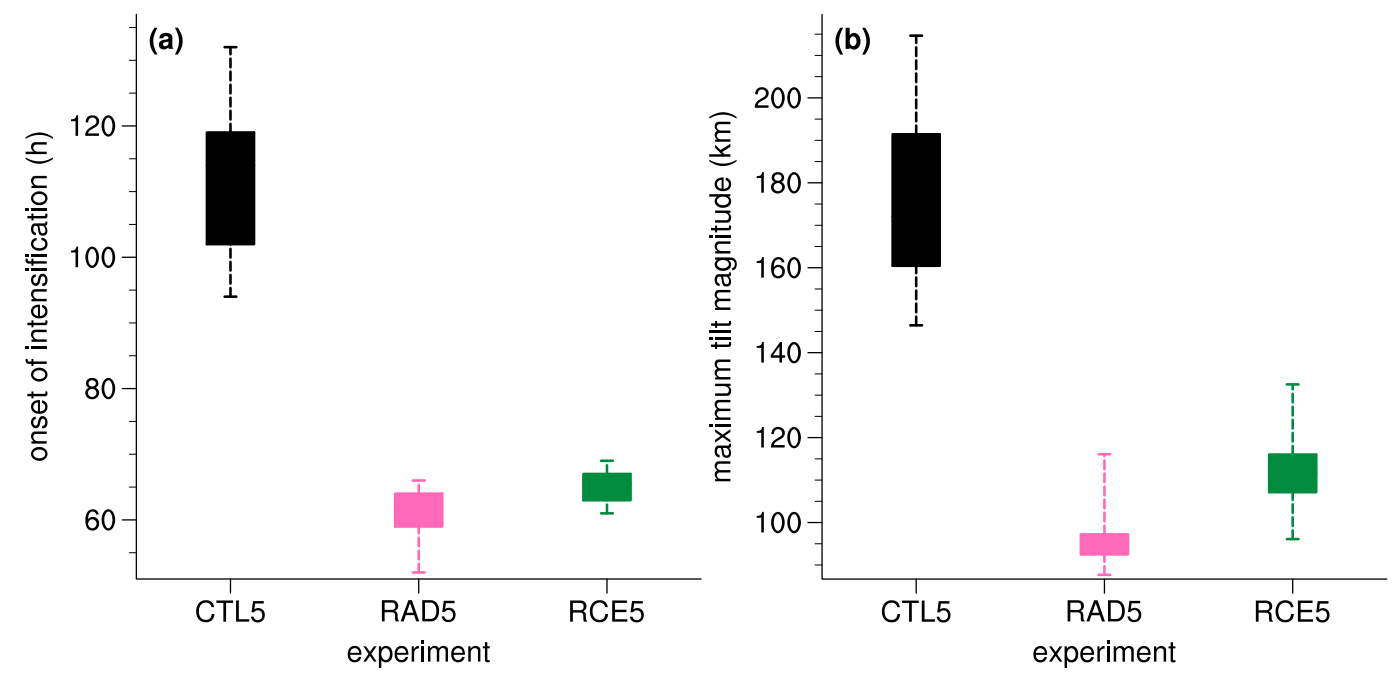

FIG. 5. Boxplots of (a) onset of intensification and (b) maximum tilt magnitude from the CTL5 (black), RAD5 (pink), and RCE5 (green) ensembles. Boxes span the interquartile range (25th-75th percentiles) and whiskers extend from minima to maxima.

Radiation also extends the threshold of shear magnitudes that allows intensification and that shows the largest intensity variability. This study used a similar setup to Tao and Zhang (2015), who found that intensification only happened with shear magnitudes below $7.5 \mathrm{~m} \mathrm{~s}^{-1}$ and that the largest intensity variability happened for moderate shear magnitudes of $5-6 \mathrm{~s}^{-1}$. That result is also true with the configuration used in this study as demonstrated by the maximum intensity of experiments with shear magnitudes between 2.5 and $12.5 \mathrm{~m} \mathrm{~s}^{-1}$ (Fig. 7a). Intensification only happens under shear magnitudes below $7.5 \mathrm{~m} \mathrm{~s}^{-1}$ without radiation; however, that threshold increases to $12.5 \mathrm{~m} \mathrm{~s}^{-1}$ when including radiation. Among the ensembles that show intensification, the largest variability in the onset of intensification appears under $5 \mathrm{~m} \mathrm{~s}^{-1}$ shear without radiation but under $10 \mathrm{~m} \mathrm{~s}^{-1}$ with radiation (Fig. 7b). This result is important because it suggests that largescale processes (e.g., radiation, background thermodynamics) can modulate uncertainty growth in numerical simulations of tropical cyclones-a result that was also discussed by Judt et al. (2016). With or without radiation, the largest intensity variability happens at the high end of shear magnitudes that allow intensification.

The ability of a tropical cyclone to intensify in idealized simulations with shear depends partially on the magnitude of vortex tilt and the likelihood of vortex tilt reduction (cf. section 1). The experiments without radiation and with shear magnitudes exceeding $5 \mathrm{~m} \mathrm{~s}^{-1}$ simulate 400-900-hPa tilt magnitudes exceeding $300 \mathrm{~km}$, as demonstrated by the distributions of maximum tilt magnitude within each ensemble (Fig. 7c). Those simulated tropical cyclones are unable to undergo tilt reduction and symmetrization; therefore, intensification does not happen within the 8-day simulation period. The experiments with radiation simulate smaller vortex tilt magnitudes than their counterparts without radiation at shear magnitudes below $12.5 \mathrm{~m} \mathrm{~s}^{-1}$ (Fig. 7c). Those experiments show tilt reduction and symmetrization leading to the onset of intensification. The contrasting tilt magnitudes with and without radiation suggest that thermodynamic processes, modulated herein by radiation, also impact the vortex and precipitation asymmetries that modulate tropical cyclone intensity changes under moderate shear.

These results have exposed a large sensitivity of tropical cyclone structure, evolution, and predictability in sheared environments to radiation. That sensitivity, however, may be unique to the choice of model, physics, background conditions, and other aspects of the simulations presented here. Notwithstanding this limitation, the simulations inspire many questions that could help expand our knowledge about the complex problem of tropical cyclone-shear interactions, such as the following examples:

- Why does the azimuthal migration of asymmetric precipitation and the midtropospheric vortex happen earlier with than without radiation?

- How does radiation, and its impacts on the environmental thermodynamics, modulate shear-induced processes, such as vortex tilt and ventilation?

- Why is there less intensity and vortex tilt variability in RAD5 than in CTL5?

Most of those questions are related to vortex tilt evolution; however, there is no conceptual framework to 

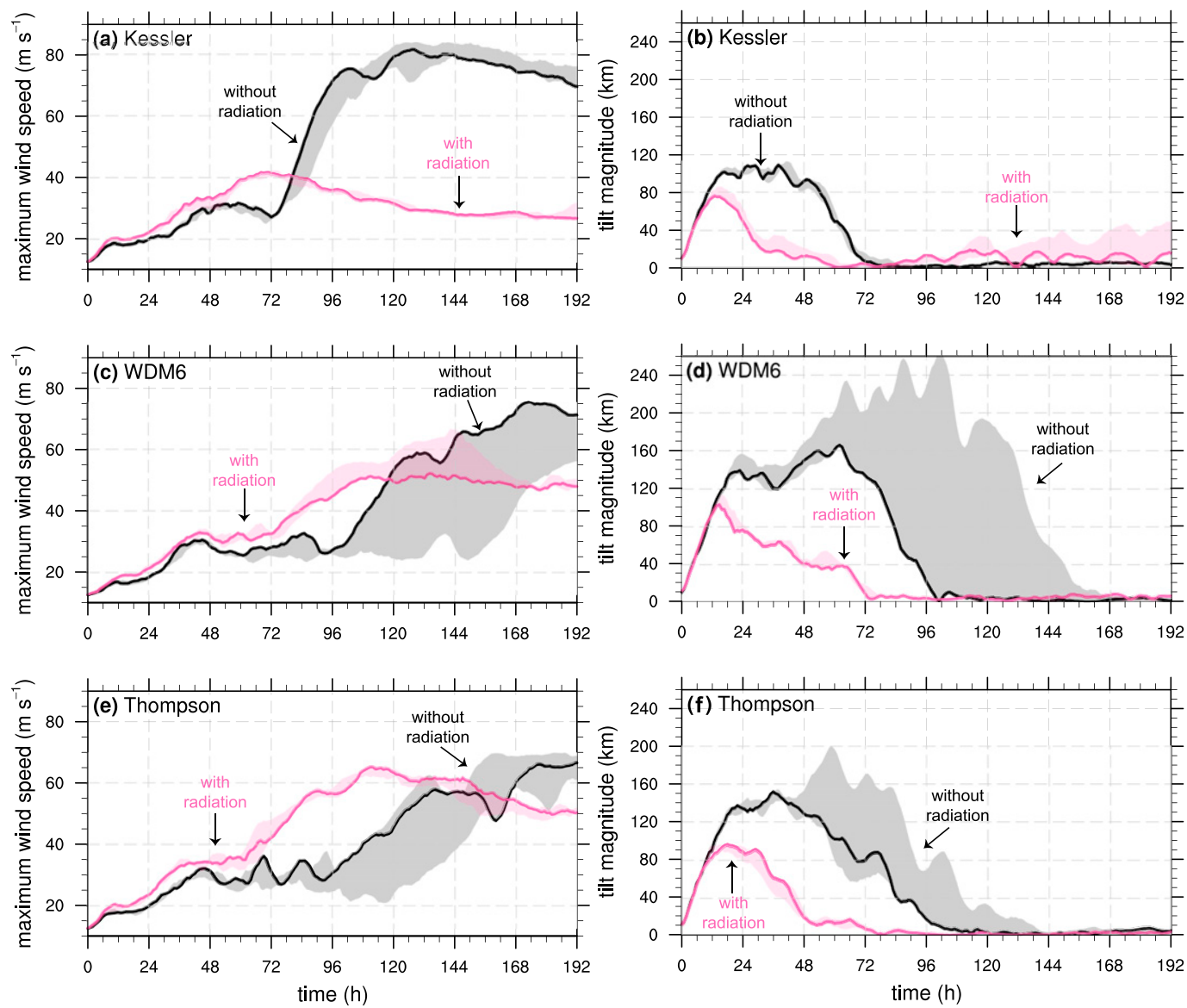

FIG. 6. Time series of hourly (left) 10-m maximum wind speed and (right) 400-900-hPa tilt magnitude from fivemember ensembles using (a),(b) Kessler, (c),(d) WDM6, and (e),(f) Thompson microphysics. In all panels, black represents simulations without radiation, pink represents simulations with radiation, lines represent the unperturbed member from each ensemble, and shading extends from ensemble-minimum to ensemble-maximum at each hour. A 6-h running mean was applied to each time series.

explain vortex tilt evolution of weak tropical cyclones. Existing knowledge about vortex tilt is primarily focused on kinematic aspects, and knowledge about thermodynamic aspects is comparatively limited. The forthcoming analysis will focus on thermodynamic aspects of the simulated tropical cyclones in CTL5 and RAD5 with a twofold purpose: to explain how including radiation leads to earlier and less variable intensification, while also learning about thermodynamic processes modulating vortex tilt evolution and variability of weak tropical cyclones.

\section{Environmental thermodynamics}

A key difference between these experiments is the greater cloud and precipitation coverage in simulations with radiation. This difference was evident in horizontal maps of composite reflectivity, and is formally quantified in Fig. 8a through a diagnostic of innermost domain cloud fraction at $24 \mathrm{~h}$. Here, cloud fraction represents the number of grid points at each level with cloud (condensed plus ice) mixing ratio greater than $1 \times 10^{-5} \mathrm{~kg} \mathrm{~kg}^{-1}$. Vertical profiles of cloud fraction show the stark differences between experiments: RAD5 members contain more clouds than CTL5 members at all levels. The differences are especially large within the boundary layer, where RAD5 members have a 3-times-higher cloud fraction than CTL5 members, and in the upper troposphere, where RAD5 members have 5 times more clouds. Yet there is more variability in the cloud coverage in RAD5 than in CTL5. Given that RAD5 and CTL5 were initialized with the same conditions and without clouds, this result suggests that radiation modifies background conditions for the development and maintenance of clouds and precipitation.

Indeed, RAD5 members exhibit different large-scale thermodynamics than CTL5 by the end of the first simulation day. Domain-averaged temperature departures 

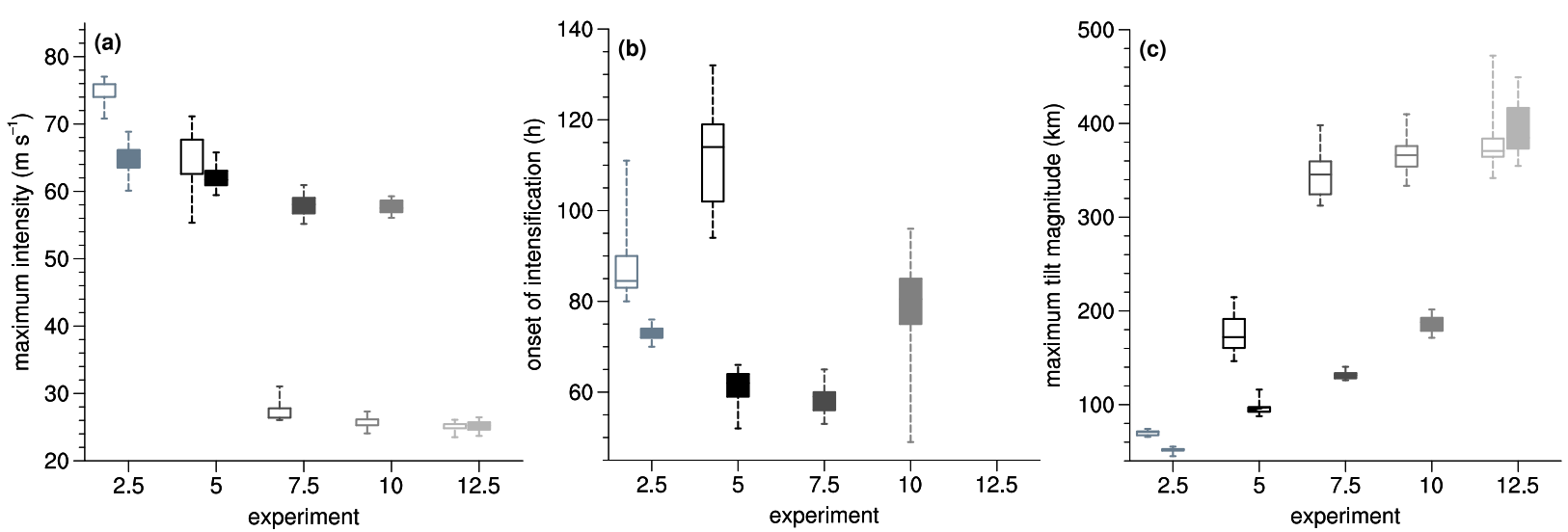

FIG. 7. Boxplots of (a) maximum intensity, (b) onset of intensification, and (c) maximum tilt magnitude from ensembles with (filled boxes) and without (empty boxes) radiation and with westerly shear magnitudes of $2.5,5,7.5,10$, and $12.5 \mathrm{~m} \mathrm{~s}^{-1}$. Colors are the same as the corresponding wind profiles in Fig. 1a. Boxes span the interquartile range (25th-75th percentiles) and whiskers extend from minima to maxima.

from the initial conditions show cooling of up to $1.4 \mathrm{~K}$ at all levels below $15-\mathrm{km}$ height and warming of up to $1.5 \mathrm{~K}$ aloft with radiation (Fig. 8b). Those temperature departures are overall consistent with the combination of clear-air longwave and shortwave radiation tendencies averaged over the first full diurnal cycle (Fig. 8c). Clearair longwave cooling dominates the net radiative tendency below $15-\mathrm{km}$ height, whereas the combination of both clear-air longwave and shortwave tendencies yield warming above cloud tops. Upper-tropospheric stabilization (i.e., warming above cooling) limits the vertical extent of upward motions and is a plausible explanation for the lower cloud-top levels with than without radiation (Fig. 8a). In contrast, the experiment without radiation shows nearly $1-\mathrm{K}$ warming near the surface and smaller temperature changes aloft. The profile of temperature changes of CTL5 and RAD5 are similar to each other below $15 \mathrm{~km}$, except shifted by about $-1 \mathrm{~K}$ in RAD5. Cooling below $15 \mathrm{~km}$ in RAD5 decreases the saturation vapor pressure without affecting the vapor pressure, thus resulting in over $10 \%$ larger clear-air relative humidities in the lower and midtroposphere with than without radiation (Fig. 8d). These thermodynamic changes during the first full diurnal cycle set the stage for the different evolutions in CTL5 and RAD5.

Three hypotheses were tested to investigate the impact of large-scale thermodynamic modifications by radiation on the different structural evolutions between CTL5 and RAD5:

1) longwave cooling in the lower troposphere resulted in less convective inhibition,

2) differential cooling in the lower troposphere resulted in more unstable conditions, and

3) free-tropospheric moistening resulted in less potential for strong downdrafts with radiation.
The first two hypotheses were motivated by Melhauser and Zhang (2014), who examined the effects of radiation on convective organization preceding the formation of Hurricane Karl (2010). The third hypothesis relates to Molinari et al. (2013), who showed that dry air and strong downdrafts inhibited symmetrization and intensification of Tropical Storm Edouard (2002). All hypotheses were tested through diagnostics of CIN, CAPE, and downdraft CAPE (DCAPE; Emanuel 1994) based on thermodynamic profiles averaged within the innermost domain. Pseudoadiabatic CIN and CAPE, including ice and with the addition of $10 \% \mathrm{~km}^{-1}$ entrainment rate following Molinari et al. (2012), were calculated for 100-m deep air parcels. Those metrics were used to diagnose how the environments were inhibiting or conducive to convective activity. DCAPE was calculated for parcels released at approximately $500 \mathrm{hPa}$ (the level that exhibited the largest DCAPE in these simulations) using pseudoadiabatic considerations as explained in Emanuel (1994). This metric was used to obtain a high-end estimate for the potential of strong downdrafts driven by evaporative cooling in subsaturated air. DCAPE is mainly affected by two factors: lower-tropospheric lapse rates and midtropospheric relative humidities (Gilmore and Wicker 1998).

The first two hypotheses cannot be accepted based on the convective instability diagnostics (Fig. 9). The initial sounding has a relatively small inhibition (approximately $8 \mathrm{~J} \mathrm{~kg}^{-1}$ ), which nearly vanishes by $6 \mathrm{~h}$ (Fig. 9a). RAD5 members exhibit smaller CIN than CTL5 members, but that only happens between 3 and $9 \mathrm{~h}$ when there is near-zero domain-averaged inhibition and after $30 \mathrm{~h}$ when the ensembles already exhibit substantially different structures. Both ensembles exhibit increasing CAPE from the onset until around $6 \mathrm{~h}$, but after that time RAD5 members are associated with 

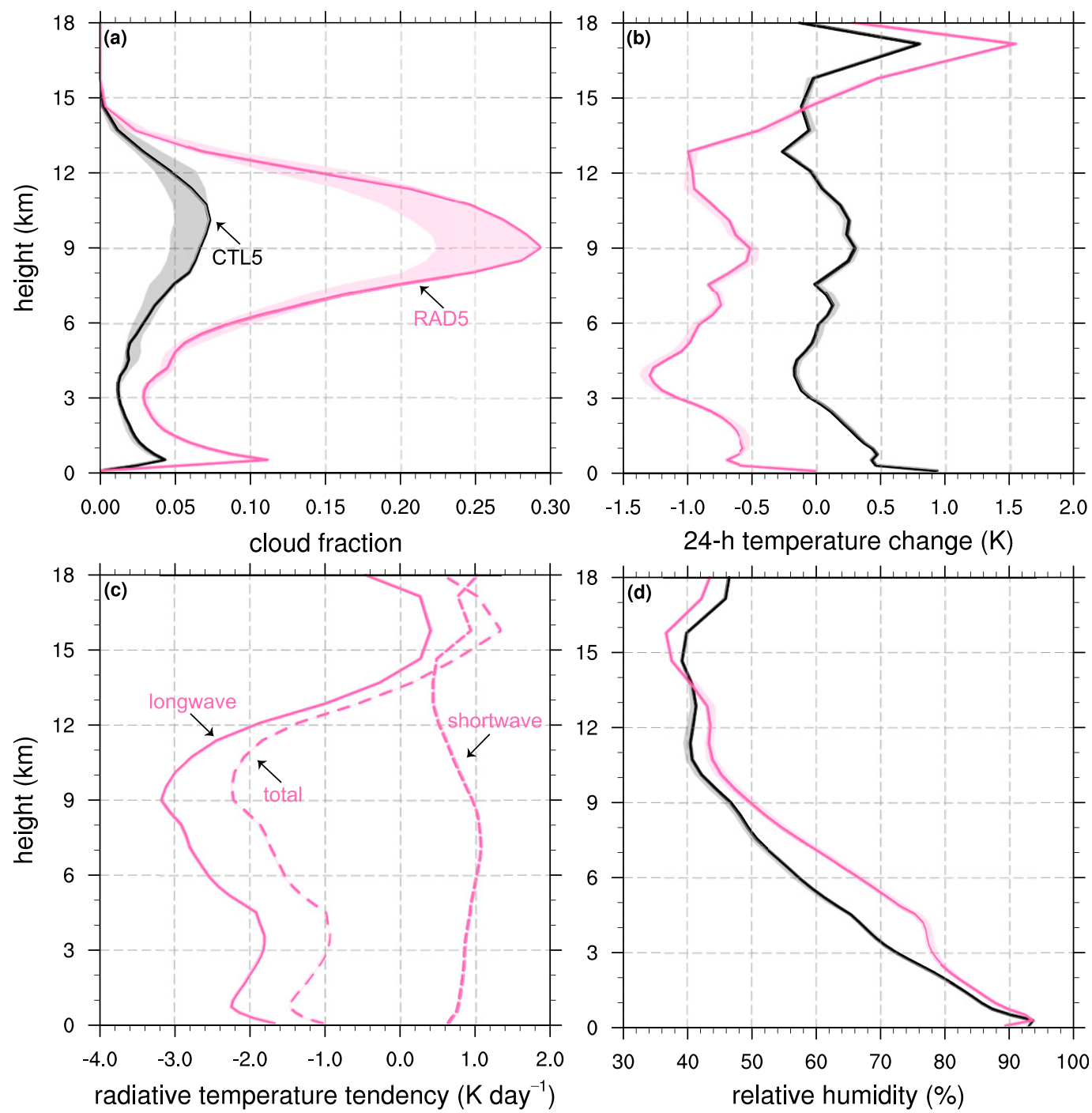

FIG. 8. Vertical profiles of (a) 24-h cloud fraction, (b) clear-air temperature difference between 24-h and the initial conditions, (c) 0-24-h clear-air radiative tendencies (solid line represents longwave, short-dashed line represents shortwave, and long-dashed line represents the net tendencies), and (d) 24-h clear-air relative humidity averaged within the innermost domain. Lines represent the unperturbed member from each ensemble; shading extends from ensemble-minimum to ensemble-maximum at each height. Colors show CTL5 (black and gray) and RAD5 (pink).

approximately $1400 \mathrm{~J} \mathrm{~kg}^{-1}$ CAPE while CTL5 members are associated with approximately $2100 \mathrm{~J} \mathrm{~kg}^{-1}$ CAPE (Fig. 9b). These results suggests that neither removal of inhibition by clear-air cooling nor lowertropospheric destabilization by differential cooling are the primary mechanisms promoting more clouds and precipitation in RAD5 than in CTL5.

Instead, the third hypothesis potentially explains the differences between RAD5 and CTL5. DCAPE decreases continuously during the first day of the ensemble with radiation, reaching approximately $510 \mathrm{~J} \mathrm{~kg}^{-1}$ by $24 \mathrm{~h}$ (Fig. 9c). The ensemble without radiation, however, exhibits only a minor reduction of DCAPE after $9 \mathrm{~h}$ and remains around $740 \mathrm{~J} \mathrm{~kg}^{-1}$-almost $40 \%$ higher than with radiation. These drastic differences are explained by both the enhanced midtropospheric relative humidity and cooler background in RAD5. For example, a separate experiment with radiation and perpetual noon insolation did not exhibit domain-averaged cooling and decreasing DCAPE (not shown).

Consistent with the contrasting DCAPE, there are large differences in lower-tropospheric equivalent potential temperature $\theta_{e}$ (Bolton 1980) near and downwind of the midtropospheric vortex and its associated 


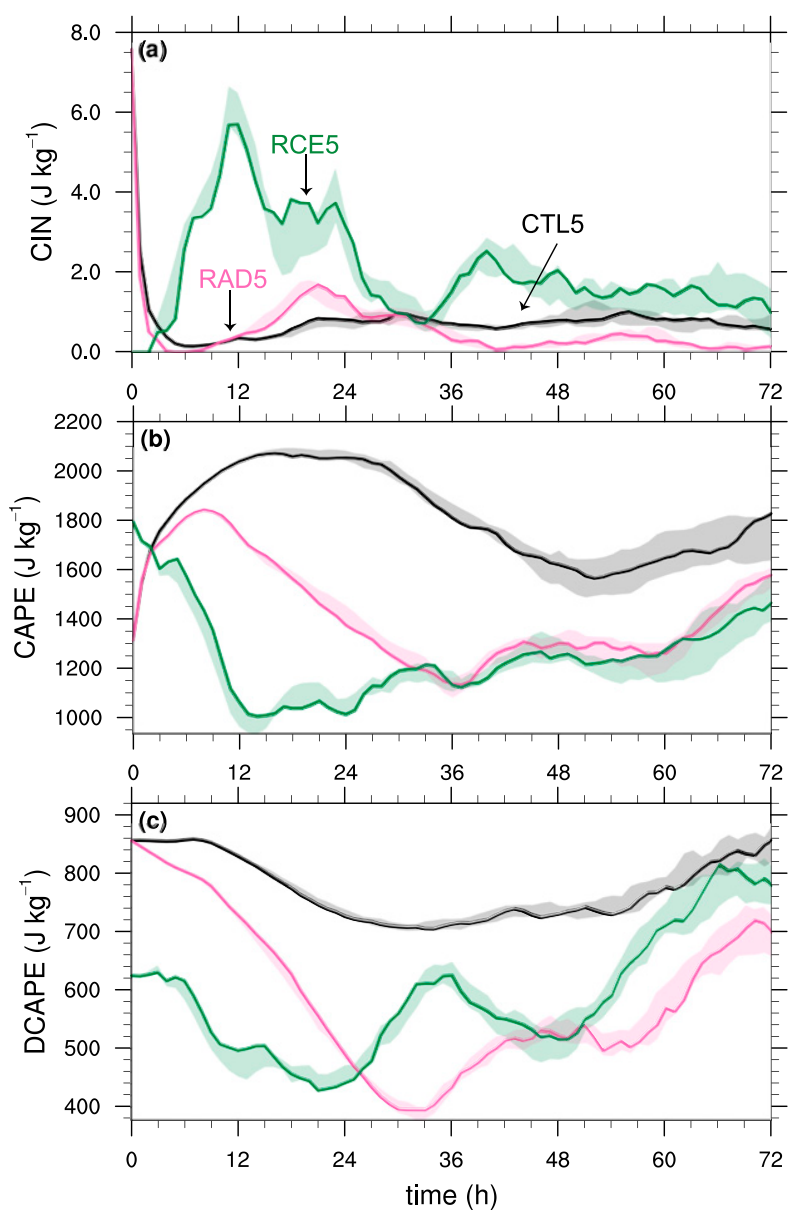

FIG. 9. Time series of hourly (a) CIN, (b) CAPE, and (c) downdraft CAPE (DCAPE) averaged within the innermost domain of CTL5 (black and gray), RAD5 (pink), and RCE5 (green). Lines represent the unperturbed member from each ensemble; shading extends from ensemble-minimum to ensemble-maximum at each hour.

precipitation (Fig. 10). These differences are illustrated through maps of 950-hPa azimuthally asymmetric $\theta_{e}$ with respect to the $900-\mathrm{hPa}$ center at times when the midtropospheric vortex was located at a similar angle $\left(45^{\circ}\right)$ in the unperturbed members from CTL5 and RAD5 (Figs. 10a,c). Both experiments exhibit low- $\theta_{e}$ air below and azimuthally downwind of the midtropospheric vortex - a result of precipitative downdrafts and spreading cold pools. CTL5, however, is associated with more and stronger cold pools than RAD5. This result is consistent throughout the azimuthal migration of the midtropospheric vortex, as demonstrated by azimuth-time analyses of azimuthally asymmetric $\theta_{e}$ averaged within a $50-\mathrm{km}$ ring centered on the midtropospheric vortex (Figs. 10b,d). Evidently, CTL5 is exposed to cooler, drier air reaching the lower troposphere because of the increased DCAPE and potential for downdrafts compared to RAD5.
These results illustrate the large-scale thermodynamic changes induced by radiation and its impacts on lower-tropospheric entropy; however, those changes may be an artifact of using an initial sounding from observations. To test for that possibility, an additional 20-member ensemble (RCE5 hereafter) including radiation was produced with a sounding in approximate radiative-convective equilibrium, given by the model configuration, similar to Nolan and Rappin (2008), Rappin and Nolan (2012), Zhou (2015), and Murthy and Boos (2018). The initial sounding (Fig. 1b) for RCE5 was obtained from the domain-averaged, timeaveraged conditions of the last 20 days of a 100-day simulation on a single, small domain spanning $100 \mathrm{~km} \times$ $100 \mathrm{~km}$ with $2-\mathrm{km}$ grid spacing. The simulation was initialized with the moist tropical sounding of Dunion (2011). All other model specifications, including the wind profile, were left the same as in RAD5. An approximate radiative-convective equilibrium was reached around 30 days per the diagnostic of domain-averaged, vertically integrated frozen moist static energy (not shown).

RCE5 members do not exhibit clear-air cooling around the tropical cyclone (not shown), but their initial sounding is cooler and closer to saturation than the initial sounding of CTL5 and RAD5 (Fig. 1b). Although RCE5 members exhibit increasing CIN and decreasing CAPE (Figs. 9a,b), that ensemble is also associated with relatively small DCAPE (Fig. 9c). The resulting intensity evolution in RCE5 is consistent with RAD5 (Fig. 11a): the simulated tropical cyclone undergoes a gradual intensification during the first $24 \mathrm{~h}$, followed by nearsteady-state intensity until undergoing a steep intensification period between 84 and $120 \mathrm{~h}$. As in RAD5, the onset of intensification happens before $72 \mathrm{~h}$ and with small variability among ensemble members (Fig. 5a). Likewise, vortex tilt and its evolution are comparable between RCE5 and RAD5 (Figs. 5a and 11b,c). Although the imposition of a vortex in the initial conditions may influence the evolution of the simulated tropical cyclone, these results confirm that background thermodynamics, as affected by radiation in RAD5 or by the initial sounding in RCE5, influence the evolution of simulated tropical cyclones in shear.

\section{Ventilation and vortex tilt}

With less energy to fuel convective downdrafts and weaker cold pools, RAD5 members could experience less ventilation than CTL5 members. Ventilation is a known effect of vertical wind shear; however, previous studies have focused on the effects of ventilation on either pregenesis disturbances or mature cyclones. RiosBerrios et al. (2018) suggested that, for weak tropical 

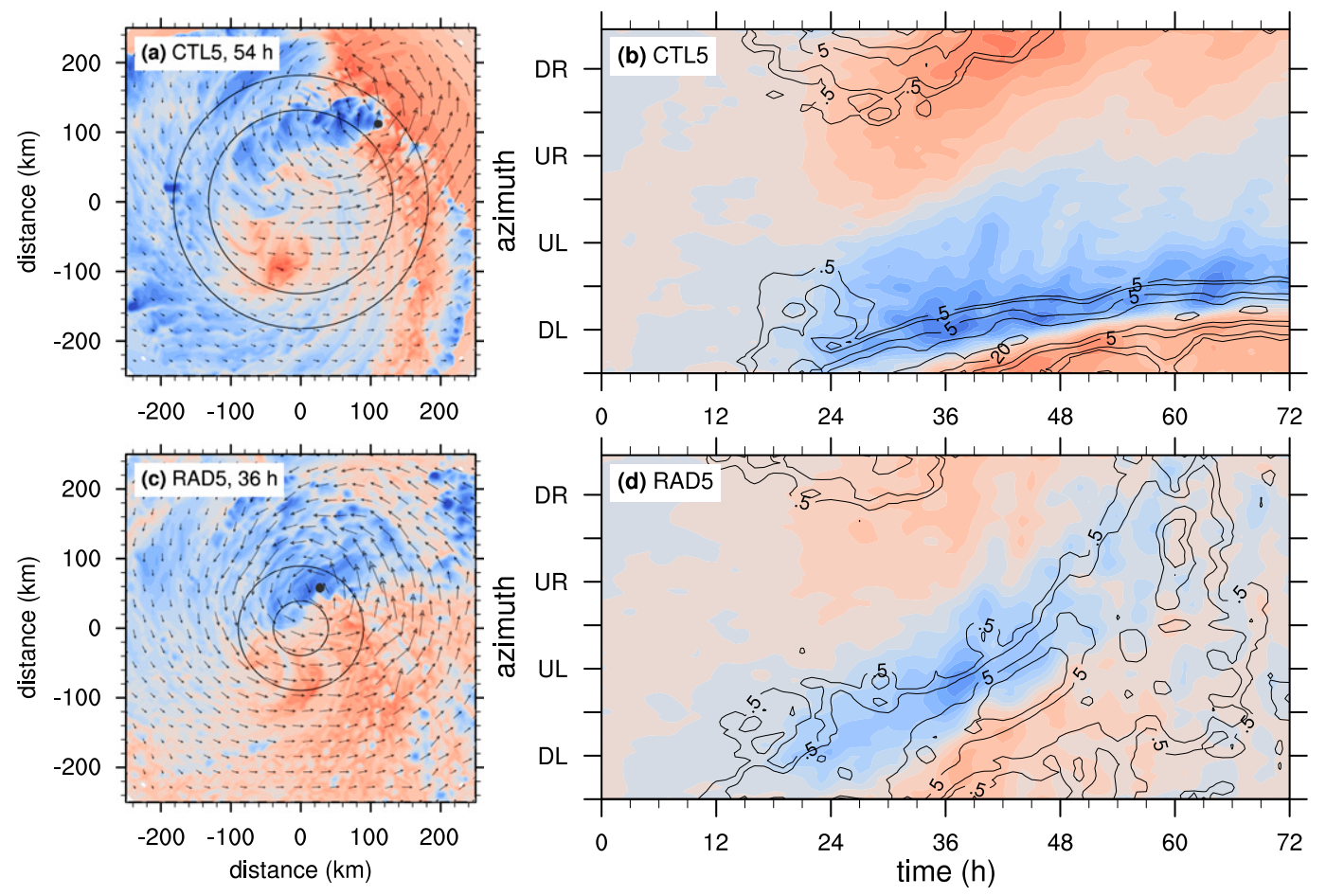

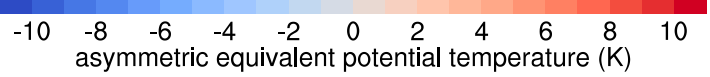

FIG. 10. (left) Horizontal maps of 950-hPa azimuthally asymmetric $\theta_{e}$ (shading; every $1 \mathrm{~K}$ ) and 400-hPa horizontal winds (vectors) centered on the 900-hPa center of the unperturbed member from (a) CTL5 and (c) RAD5. (right) Time-azimuth analysis of hourly $950-\mathrm{hPa}$ azimuthally asymmetric equivalent potential temperature (shading; every $1 \mathrm{~K}$ ) and column-integrated total condensate (contours; plotted at 0.5, 1.0, 5.0, 10.0, and 20.0 mm) averaged within a 50-km-wide ring centered on the 400-hPa center of the unperturbed member from (b) CTL5 and (d) RAD5. A sample ring is shown in (a) and (c). Azimuths are identified as quadrants with respect to the $900-\mathrm{hPa}$ center as follows: downshear right (DR), downshear left (DL), upshear right (UR), and upshear left (UL).

cyclones such as those studied here, the impact of ventilation on asymmetric convection and on the evolution of vortex tilt needs attention. Figure 10 hints at different ventilation scenarios in the experiments considered here, thus motivating the forthcoming analysis.

Ventilation and its effects on asymmetric convection were examined through an isentropic analysis of the simulated tropical cyclones. Isentropic analysis was introduced by Pauluis and Mrowiec (2013) and was applied to tropical cyclones by Mrowiec et al. (2016), Alland et al. (2017), and Pauluis and Zhang (2017). The main goal of isentropic analysis is to map a variable from a Cartesian framework into a height-entropy framework. This mapping is accomplished via

$$
\langle\Lambda\rangle\left(\theta_{e}^{\prime}, z, t\right)=\int_{x} \int_{y} \Lambda(x, y, z, t) \delta\left[\theta_{e}^{\prime}-\theta_{e}(x, y, z, t)\right] d x d y,
$$

where $\Lambda$ is the variable to be mapped into the heightentropy space, $\theta_{e}$ is used as a proxy for entropy and is calculated with Eq. (43) of Bolton (1980), the prime symbol signifies that $\theta_{e}$ is binned into discrete values, and $\delta$ is the Dirac delta. Here, the variable of interest was the vertical mass flux:

$$
\begin{aligned}
\langle\rho w\rangle\left(\theta_{e}^{\prime}, z, t\right)= & \int_{x} \int_{y}[\rho(w-\bar{w})](x, y, z, t) \\
& \times \delta\left[\theta_{e}^{\prime}-\theta_{e}(x, y, z, t)\right] d x d y,
\end{aligned}
$$

where $\rho$ is dry-air density, $w$ is vertical velocity, and the overbar represents a domain average following Mrowiec et al. (2016). A benefit of using this isentropic analysis with vertical mass flux is that air motions are separated into high-entropy rising motions and low-entropy sinking motions, thus allowing to simultaneously compare vertical mass fluxes and ventilation between experiments. Differences between simulations will be further illustrated with an isentropic weighted average, defined as

$$
\left\langle\overline{\theta_{e}}\right\rangle=\frac{\overline{\langle\rho w\rangle \theta_{e}}}{\overline{\langle\rho w\rangle}},
$$



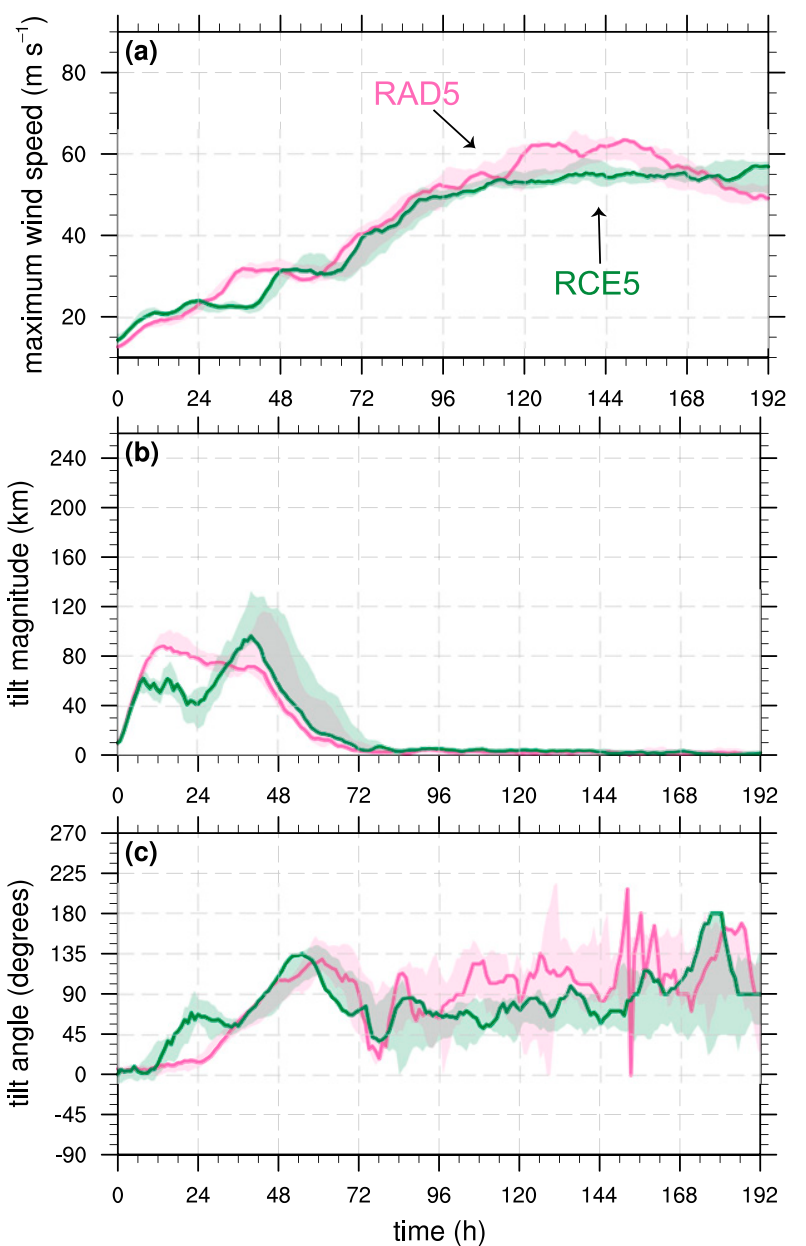

FIG. 11. Time series of hourly (a) 10-m maximum wind speed, (b) 400-900-hPa tilt magnitude, and (c) 400-900-hPa tilt angle from RAD5 (pink) and RCE5 (green). Lines represent the unperturbed member from each ensemble; shading extends from ensembleminimum to ensemble-maximum at each hour. A 6-h running mean was applied to each time series.

where the overbar represents an average over $\theta_{e}^{\prime}$ bins and $w$ will be taken as either positive (upward mass fluxes) or negative (downward mass fluxes). Isentropic analysis and averaging may be influenced by the $\theta_{e}$ formulation used; however, the main focus here is a comparison across experiments using the same $\theta_{e}$ definition in each case.

The isentropic analysis of vertical mass flux was obtained during $24-48 \mathrm{~h}$, a period during which the convective structures and tilt evolutions differ between CTL5 and RAD5 (cf. section 3). Moreover, the analysis was limited to the main region of convective updrafts and downdrafts, which is approximately an area extending to $100-\mathrm{km}$ radius from the midtropospheric center. Figures $12 \mathrm{a}$ and $12 \mathrm{~b}$ show the resulting isentropic mass flux and area-averaged $\theta_{e}$, both of which were time averaged from hourly output of the unperturbed members from each ensemble. In both simulations, ascending motions primarily happen at relatively high $\theta_{e}$ and downward motions primarily happen at relatively low $\theta_{e}$. This pattern is also illustrated by the average $\theta_{e}$ weighted by upward and downward mass fluxes (Fig. 12c). On average, ascending motions in RAD5 happen at smaller $\theta_{e}$ than in CTL5-a result of the cooler temperatures in simulations with radiation.

Ventilation can be diagnosed qualitatively from the isentropic analysis because $\theta_{e}$ is approximately conserved following moist air parcels. A quantitative analysis would require in-depth analysis (e.g., Riemer and Laliberté 2015), which is beyond the intended analysis here. As air rises from the surface, its $\theta_{e}$ decreases through entrainment of cool, dry air from the environment. This process, which is akin to the ventilation pathway studied by Tang and Emanuel (2012), is less pronounced in RAD5 than in CTL5 (Fig. 12c). Ascending air parcels of CTL5 begin with average $\theta_{e}$ of $358 \mathrm{~K}$ near the surface; their average $\theta_{e}$ decreases to $348 \mathrm{~K}$ by the time they reach $4 \mathrm{~km}$. In contrast, updrafts of RAD5 initiate with average $\theta_{e}$ of $352 \mathrm{~K}$ near the surface and reach $4 \mathrm{~km}$ with $\theta_{e}$ of $347 \mathrm{~K}$. This $5-\mathrm{K}$ reduction in RAD5-or half the reduction in CTL5-suggests less lateral ventilation in RAD5 and RCE5. Above 4-km height, both RAD5 and CTL5 exhibit increasing $\theta_{e}$ due to freezing. RAD5 is associated with weaker upper-tropospheric upward mass fluxes than CTL5-a result of weaker stratiform updrafts, as will be shown below.

Drastic differences appear in the lower-tropospheric ventilation pathway, which is represented by descending air parcels entering the lower troposphere (Riemer et al. 2010). Descending motions have the largest contribution to the isentropic mass flux around and below 4-km height (Figs. 12a,b). RAD5 is associated with weaker downward mass fluxes than CTL5. Furthermore, descending air motions in RAD5 happen at comparable $\theta_{e}$ values as in CTL5 even though ascending air motions in RAD5 happen at smaller $\theta_{e}$ than in CTL5 (Fig. 12c). The smaller $\theta_{e}$ difference between ascending and descending air motions in RAD5 implies that air parcels lose less entropy due to ventilation with than without radiation-a potential result of the different large-scale thermodynamic profiles. These results demonstrate that RAD5 is associated with weaker downward fluxes of low-entropy air in the lower troposphere, which may be a result of both weaker updrafts aloft and less potential for strong downdrafts from the background thermodynamics.

Downward fluxes of low-entropy air could be triggered by tilt-induced downdrafts, precipitation-induced downdrafts through melting of hydrometeors and their subsequent evaporation in subsaturated air, or a combination of 

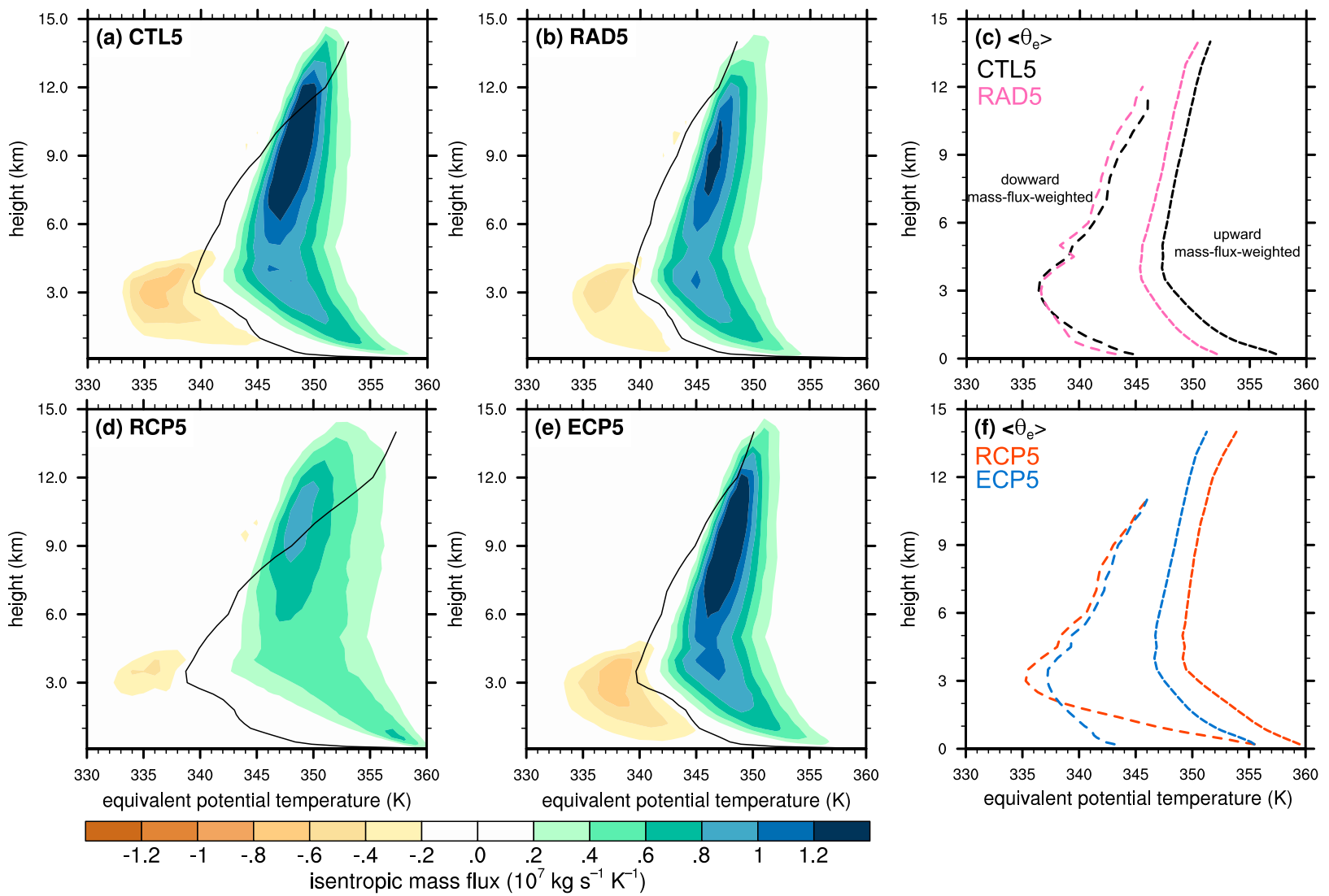

FIG. 12. (a),(b),(d),(e) Isentropic mass flux (shading; every $0.2 \times 10^{7} \mathrm{~kg} \mathrm{~s}^{-1} \mathrm{~K}^{-1}$ ), averaged between 24 and $48 \mathrm{~h}$, of vertical motions within a 100-km radius from the 400-hPa center of the unperturbed members from (a) CTL5, (b) RAD5, (d) RCP5, and (e) ECP5. Lines represent $\theta_{e}$ averaged within the same domain as the isentropic analysis. (c) Vertical profiles of (short-dashed lines) upward and (longdashed lines) downward mass-flux-weighted equivalent potential temperature from the unperturbed members of CTL5 (black) and RAD5 (pink). (f) As in (c), but for the unperturbed members of RCP5 (orange) and ECP5 (blue).

both. The isentropic analysis suggests that melting and evaporation are the most likely drivers of the downward fluxes because they happen at and below the melting level. Riemer et al. (2013) previously demonstrated that melting can substantially increase downdrafts in sheared tropical cyclones. Here, the result of the precipitation-driven downdrafts is a series of cold pools below and azimuthally downwind of the midtropospheric vortex and its associated precipitation, as previously discussed (Fig. 10).

Low-entropy air spreads over more azimuths while precipitation is more azimuthally restricted in CTL5 than in RAD5. The asymmetric precipitation, represented by column-integrated total condensate (black contours in Figs. 10b,d), lags behind the spreading lowentropy air. Cold pools inhibit the azimuthal migration of convection because negatively buoyant air parcels cannot ascend until they recover through surface heat and moisture fluxes, turbulent mixing, detrainment below cloud base, shortwave heating, and longwave heating below cloud base. With relatively weaker downward fluxes of low-entropy air, RAD5 (Figs. 10c,d) exhibits weaker and fewer cold pools than CTL5 (Figs. 10a,b). Consequently, there is more ascent and cloudiness over wider azimuths with the more nearly saturated background conditions of RAD5. Cold pools and the asymmetric precipitation coevolve at similar time scales, demonstrating their strong coupling.

Ventilation and vortex tilt evolution are linked, in part, via the asymmetric vertical motions and their coupling with the midtropospheric vortex. Rios-Berrios et al. (2018) demonstrated that the midtropospheric vortex and the asymmetric convection are strongly coupled to each other-a process that alters one also alters the other. Their study also demonstrated that the vertical mass flux profile within and around the midtropospheric vortex can influence vortex tilt evolution. In particular, a more "bottom-heavy" vertical mass flux profile is conducive to near-surface vorticity spinup and 

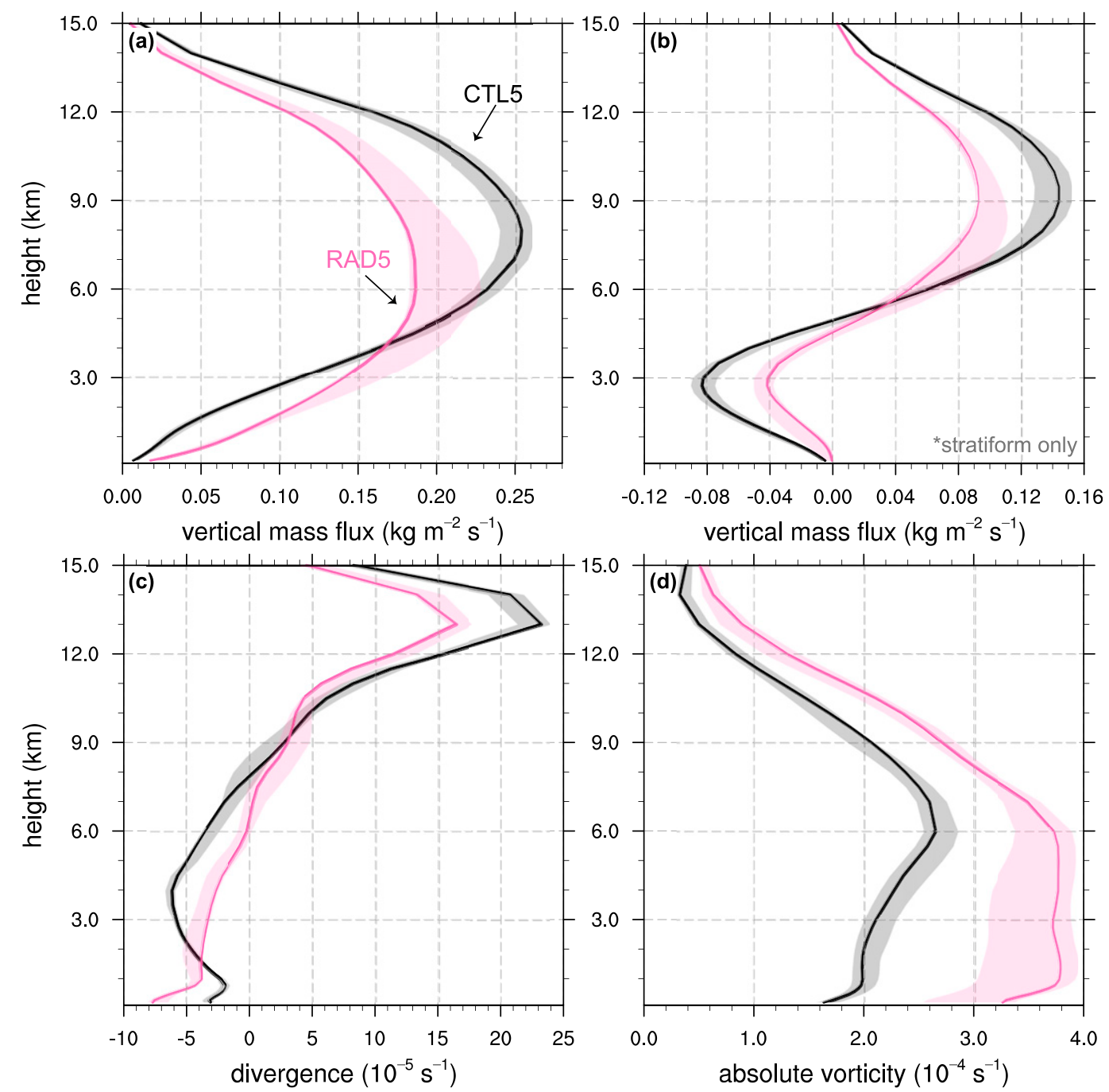

FIG. 13. Vertical profiles of (a) total vertical mass flux, (b) stratiform only vertical mass flux, (c) total divergence, and (d) absolute vorticity time averaged between 24 and $48 \mathrm{~h}$ and area averaged within a 100-km radius from the 400-hPa center of circulation of the unperturbed members from CTL5 (black) and RAD5 (pink).

vortex tilt reduction. Area-averaged and time-averaged vertical mass flux profiles (Fig. 13a) over the same region as the isentropic analysis demonstrate that RAD5 members are associated with stronger upward fluxes below $4 \mathrm{~km}$ and weaker upward fluxes aloft, resulting in a more bottom-heavy profile than in CTL5. Those differences are largely contributed by stratiform rain processes-separating grid points between convective and stratiform with the method of Rogers (2010) shows weaker downward mass fluxes due to stratiform motions below $5 \mathrm{~km}$ in RAD5 than in CTL5 (Fig. 13b). Likewise, RAD5 is associated with weaker upward mass fluxes due to stratiform motions above $6 \mathrm{~km}$ likely resulting in the production of fewer hydrometeors.

Vorticity spinup via vortex stretching depends in part on the vertical gradient of the vertical mass flux profile.
With a more bottom-heavy vertical mass flux profile, RAD5 is associated with stronger area-averaged convergence near the surface than CTL5 (Fig. 13c). Vorticity is also enhanced practically at all levels below the midtropospheric vortex of RAD5 (Fig. 13d), possibly due to the slightly stronger tropical cyclone or due to the smaller vortex tilt in RAD5 than in CTL5 (cf. Fig. 2). The combination of stronger near-surface convergence and vorticity results in stronger near-surface vortex stretching; this process spins up vorticity below the midtropospheric vortex and leads to tilt reduction via a similar pathway to the restructuring process identified by Rios-Berrios et al. (2018). An important difference is that, with radiation, near-surface vorticity spinup via vortex stretching reduces the tilt magnitude and allows for an earlier vortex tilt reduction. Hence, tilt 
reduction in RAD5 happens as the lower-tropospheric center slowly reforms near the cyclonically migrating midtropospheric vortex (cf. Fig. 4) instead of waiting until the midtropospheric vortex enters upshear left as it happens in CTL5 (Rios-Berrios et al. 2018).

\section{Sensitivity experiments}

This link between ventilation, cold pools, and vortex tilt was further confirmed through sensitivity experiments. The underlying process was hypothesized to be rain evaporation below cloud base, which is a parameterized process in microphysics schemes. To this end, two additional 20-member ensembles were produced with a modified version of WRF in which cold pools were artificially weakened or strengthened by modifying rain evaporation directly in the microphysics scheme. This method dates back to Rotunno and Klemp (1985) and has been used extensively to examine the sensitivity of convective systems to cold pool intensity.

In WSM6, rain evaporation is parameterized according to Eq. (B14) from Dudhia (1989). The sensitivity experiments presented here had the exact same initial conditions as CTL5 and no radiation, but rain evaporation at each grid point was decreased or increased via

$$
\mathrm{RE}^{*}=(1+\alpha) \mathrm{RE},
$$

where $\mathrm{RE}$ is the original rain evaporation predicted by WSM6, $\mathrm{RE}^{*}$ is the modified rain evaporation, and $\alpha$ is a parameter that controls the change in RE. This method affects both water vapor mixing ratio and temperature below cloud base. Two ensembles were produced: 1 ) an experiment with reduced cold pools (RCP5 hereafter) obtained with $\alpha=-0.9$, and 2) a counterpart experiment with enhanced cold pools (ECP5 hereafter) using $\alpha=0.9$. This value of $\alpha$ was chosen to substantially weaken or strengthen cold pools. The experiments have the desired effects because their isentropic analyses show weaker (Fig. 12d) and stronger (Fig. 12e) downward mass fluxes at low $\theta_{e}$ in RCP5 and ECP5, respectively. Downward fluxes of low-entropy air have the largest effects on the average $\theta_{e}$ within and around the midtropospheric vortex (Fig. 12d)

Results from RCP5 and ECP5 illustrate the role of lower-tropospheric ventilation and the resulting cold pools in the idealized tropical cyclone simulations with shear. Reduced lower-tropospheric ventilation via reduced rain evaporation results in earlier, less variable, and steeper intensification rates than in CTL5 (Figs. 14a and $15 \mathrm{a}$ ). The evolution of this experiment is very similar to the sensitivity experiment with warm-rain only microphysics (Fig. 6a), possibly pointing at the role of melting and subsequent rain evaporation as suggested by Riemer et al. (2013). In contrast, increasing the lower-tropospheric ventilation results in more variable onsets of intensification and less pronounced intensification rates (Figs. 14a and 15a). Overall, ECP5 members show later intensification than in CTL5, but the variability in ECP5 is so large that some members overlap with CTL5 (Figs. 14a and 15a). This result speaks to the importance of using ensembles to account for intensity and structural variability.

Although changing rain evaporation inevitably changes other factors through nonlinear feedbacks (e.g., Figs. 12df), the sensitivity experiments confirm the role of lowertropospheric ventilation and the resulting cold pools on vortex tilt. RCP5 members develop less tilted vortices (Fig. 15b), exhibit faster azimuthal migrations, and experience earlier tilt reductions than CTL5 (Figs. 14b,c). ECP5, however, develop more tilted vortices and show overall slower tilt reductions than CTL5 despite the large overlap between some of their members. This result demonstrates how precipitationdriven downdrafts and lower-tropospheric ventilation can largely influence vortex tilt dynamics. Intriguingly, the variability of intensity and tilt magnitude is sensitive to lower-tropospheric ventilation as demonstrated by the smaller spread of those quantities in RCP5 than in both CTL5 and ECP5 (Fig. 15a). This result is important because it points to cold pools as potential sources of uncertainty in numerical model predictions of tropical cyclones interacting with vertical wind shear.

\section{Conclusions}

A primary objective of this study was to document the effects of radiation on idealized numerical simulations of weak tropical cyclones in sheared environments. This objective was accomplished through the comparison of 20-member ensembles with and without radiation. Including radiation yields earlier and less variable intensification at stronger shear magnitudes than in the commonly used idealized framework without radiation. Those impacts were traced to changes in environmental thermodynamics and their impacts on the asymmetric precipitation that accompanies the midtropospheric vortex. An ensemble with radiation and $5 \mathrm{~m} \mathrm{~s}^{-1}$ westerly shear exhibited cooler and more saturated conditions than an ensemble without radiation after the first full diurnal cycle, thus limiting the amount of energy available to fuel strong downdrafts with radiation. A companion ensemble with background thermodynamics in radiative-convective equilibrium, given by the model configuration and 

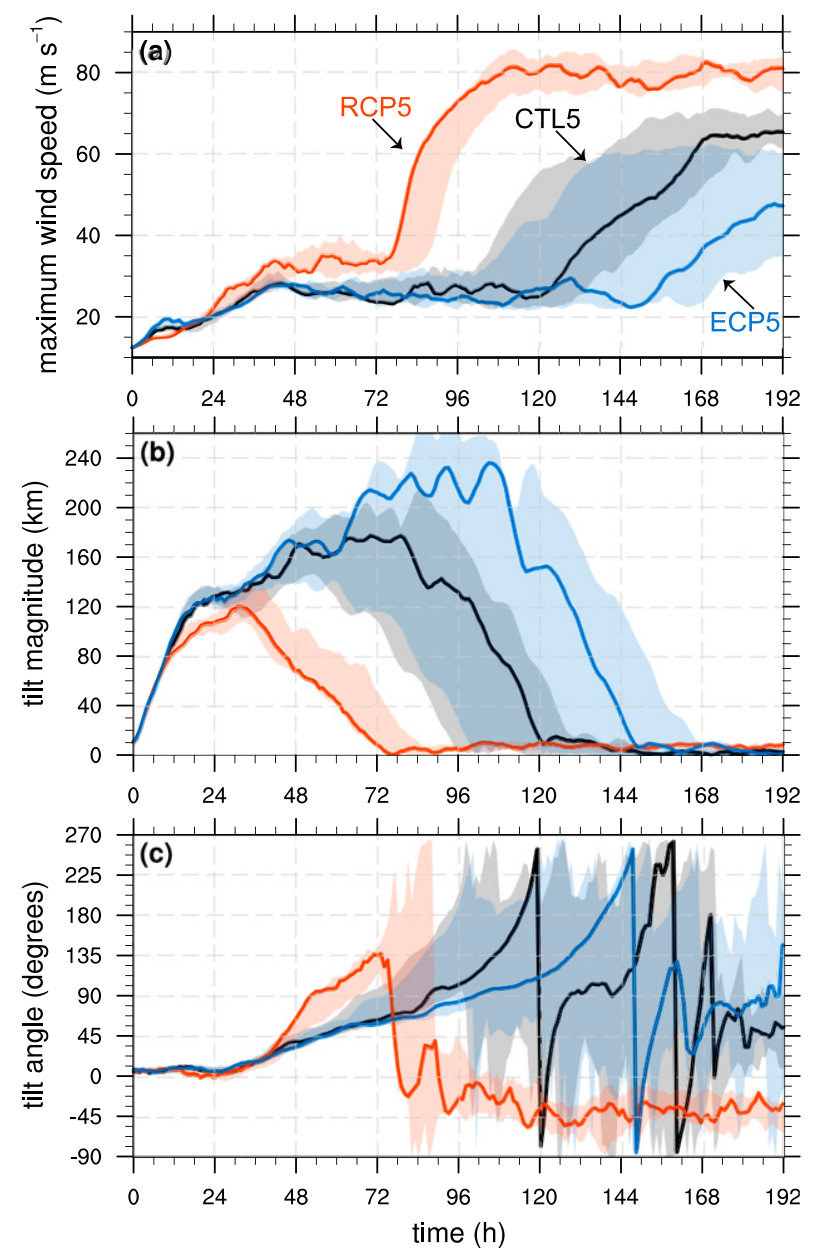

FIG. 14. Time series of hourly (a) 10-m maximum wind speed, (b) 400-900-hPa tilt magnitude, and (c) 400-900-hPa tilt angle from CTL5 (black and gray), RCP5 (orange), and ECP5 (blue). Lines represent the unperturbed member from each ensemble; shading extends from ensemble-minimum to ensemble-maximum at each hour. A 6-h running mean was applied to each time series.

physics, confirmed the role of environmental thermodynamics on the simulated tropical cyclone with radiation.

Another objective of this work was to further elucidate how shear-induced processes, such as ventilation and vortex tilt, affect the evolution of weak tropical cyclones under sheared flow. Here, a connection was established between environmental thermodynamics, lower-tropospheric ventilation, and vortex tilt. With less energy to fuel strong downdrafts, the ensembles with radiation were associated with weaker lower-tropospheric ventilation around the midtropospheric vortex. Consequently, the experiments with radiation were also associated with weaker cold pools, less negatively buoyant air, and a broader azimuthal coverage of clouds and precipitation. Those factors aided vorticity spinup as they allowed the lower- and midtropospheric vortex to remain closer, resulting in smaller vortex tilts and earlier tilt reductions. The more expansive region of ascent could have also enhanced the upper-tropospheric outflow; although this possibility was not explored here, recent studies suggest that outflow associated with asymmetric convection can modulate tropical cyclone-environmental flow interactions (e.g., Dai et al. 2019; Ryglicki et al. 2019).

Sensitivity experiments confirmed the connection between lower-tropospheric ventilation and vortex tilt. Reducing rain evaporation, thus reducing lowertropospheric ventilation, yield smaller vortex tilt magnitudes, earlier tilt reductions, and earlier onsets of intensification; the opposite results were obtained when increasing rain evaporation. These results may explain why tropical cyclones that intensify under moderate shear do so when environmental thermodynamics (e.g., SST and midtropospheric humidity) are favorable (Rios-Berrios and Torn 2017, and references therein). Additional studies are needed to confirm this possibility, especially with more detailed analysis of experiments using different microphysics schemes. Likewise, the results may depend on other processes that interact with microphysical processes, such as boundary layer parameterizations.

The third and last objective of this work was to expose the sensitivity of intensity and vortex tilt variability to thermodynamic processes. Results from this work suggest that uncertainty associated with microphysical processes modulates the formation and strength of downdrafts, which in turn affects vortex tilt and intensity variability of tropical cyclones in sheared environments. This result is summarized in Fig. 16 through a comparison between the onset of intensification and the average downshear-left tilt magnitude (see figure caption for details) of 100 simulations with $5 \mathrm{~m} \mathrm{~s}^{-1}$ westerly shear between 200 and $850 \mathrm{hPa}$. Simulations with the weakest lower-tropospheric ventilation, modulated by rain evaporation below cloud base and by environmental thermodynamics, were associated with the smallest and least variable vortex tilt magnitudes. Intensity variability in idealized simulations is strongly related to vortex tilt variability; therefore, the largest and more variable the vortex tilt, the later and more variable is the onset of intensification. This finding potentially explains why lower-tropospheric water vapor largely influences tropical cyclone intensity predictability, as recently documented by Emanuel and Zhang (2017).

The strong relationship between the onset of intensification and vortex tilt magnitude (Pearson's correlation coefficient of 0.98 ) is promising for theoretical 

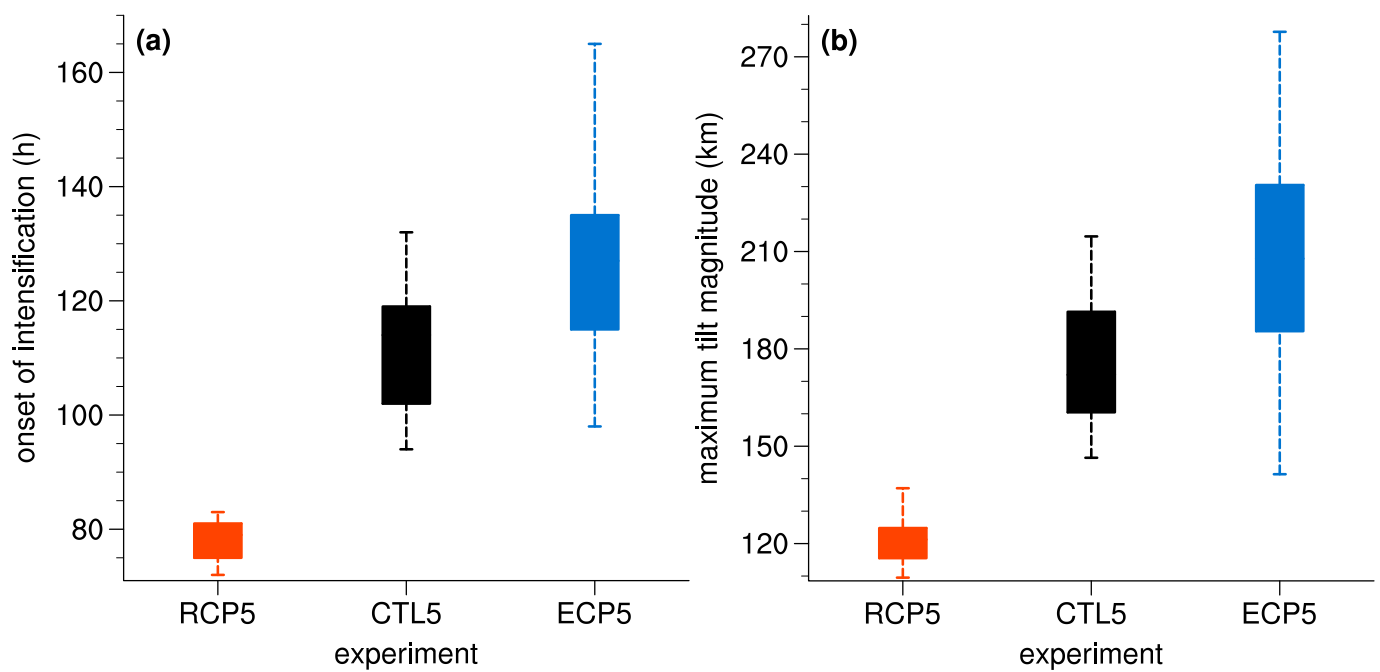

FIG. 15. Boxplots of (a) onset of intensification and (b) maximum tilt magnitude from the CTL5 (black), RCP5 (orange), and ECP5 (blue) ensembles. Boxes span the interquartile range (25th-75th percentiles) and whiskers extend from minima to maxima.

considerations (Fig. 16). Although this study considered only a set of parameters (e.g., SST, wind profile, latitude, initial vortex strength and size) with a specific model configuration, the relationship between vortex tilt and intensity is consistent with other studies that explored the sensitivity of simulated intensity to environmentalscale and convective-scale factors (e.g., Rappin and Nolan 2012; Ge et al. 2013; Zhang and Tao 2013; Tao and Zhang 2014; Onderlinde and Nolan 2014, 2016; Finocchio et al. 2016; Ryglicki et al. 2018). Such relationship implies the existence of a theoretical time scale: the larger the vortex tilt, the longer the time scale of structural changes necessary for intensification. The larger that time scale, the less likely intensification may be in the real world because other detrimental factors (e.g., increasing shear, dry air) may halt the sequence of events necessary for intensification. Derivation of that time scale requires a conceptual framework to explain vortex tilt evolution of weak tropical cyclones, as well as a comparison against existing frameworks for strong tropical cyclones (Schecter et al. 2002; Reasor et al. 2004).

Vortex tilt and intensity variability in these idealized simulations are related to nonlinear feedbacks between lower-tropospheric ventilation, cold pools, precipitation, and vortex tilt. Those feedbacks, however, depend on subgrid-scale processes parameterized in microphysics schemes that are not necessarily formulated for tropical environments. For example, rain evaporation is a parameterized process in WSM6 and other microphysics schemes; its "true" magnitude is a complicated function of raindrop size distribution and ambient humidity, among other factors. At the same time, observing cold pools over oceans is difficult with existing platforms, thus preventing progress toward improved microphysics schemes. The results presented here stress the importance of better observing, modeling, and understanding the lower troposphere (including the boundary layer) of tropical cyclones.

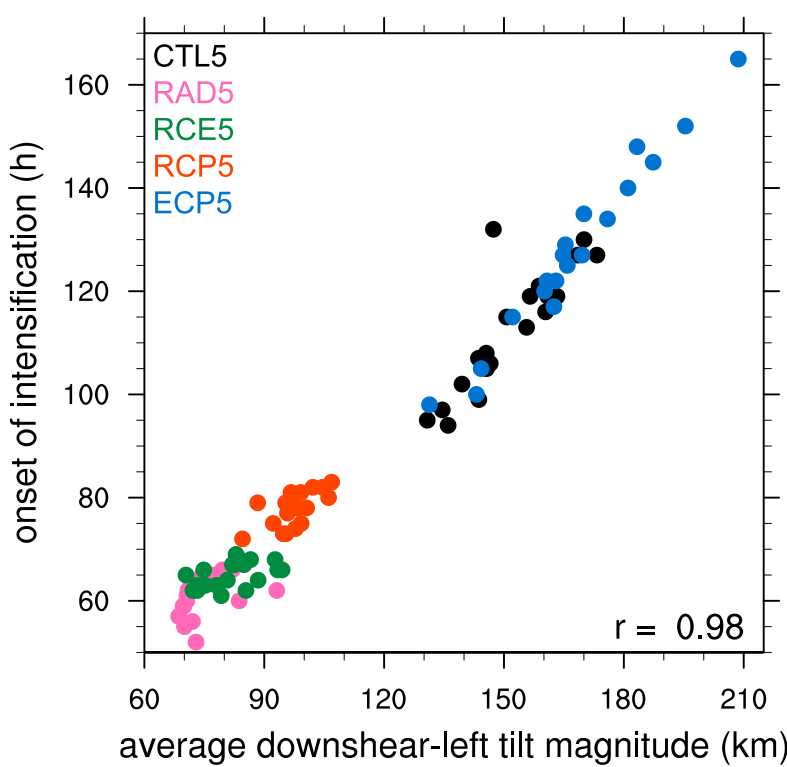

FIG. 16. Comparison between the onset of intensification and 400-900-hPa tilt magnitude averaged only during the time period when the tilt vector pointed downshear left (defined as a mathematical angle between $0^{\circ}$ and $90^{\circ}$ ). Colors represent different 20-member ensembles with the same shear magnitude: CTL5 (black), RAD5 (pink), RCE5 (green), RCP5 (orange), and ECP5 (blue). Pearson's correlation coefficient appears at the lower-right corner. 
Acknowledgments. This work benefited from discussions with Drs. Ryan Torn, Christopher Davis, George Bryan, Richard Rotunno, and other NCAR scientists. The author would like to thank Drs. David Nolan and Matthew Onderlinde for providing code to perform the idealized simulations. Insightful comments from three anonymous reviewers helped improve this manuscript. This material is based upon work supported by NCAR, which is a major facility sponsored by the National Science Foundation under Cooperative Agreement 1852977. The work was completed while the author held an NCAR's Advanced Study Program Postdoctoral Fellowship. Computing resources were provided by NCAR's Computational and Information Systems Laboratory (CISL).

\section{REFERENCES}

Alland, J. J., B. H. Tang, and K. L. Corbosiero, 2017: Effects of midlevel dry air on development of the axisymmetric tropical cyclone secondary circulation. J. Atmos. Sci., 74, 1455-1470, https://doi.org/10.1175/JAS-D-16-0271.1.

Bolton, D., 1980: The computation of equivalent potential temperature. Mon. Wea. Rev., 108, 1046-1053, https://doi.org/ 10.1175/1520-0493(1980)108<1046:TCOEPT>2.0.CO;2.

Brown, B. R., M. M. Bell, and A. J. Frambach, 2016: Validation of simulated hurricane drop size distributions using polarimetric radar. Geophys. Res. Lett., 43, 910-917, https:// doi.org/10.1002/2015GL067278.

Bu, Y. P., R. G. Fovell, and K. L. Corbosiero, 2014: Influence of cloud-radiative forcing on tropical cyclone structure. J. Atmos. Sci., 71, 1644-1662, https://doi.org/10.1175/JAS-D-13-0265.1.

Dai, Y., S. J. Majumdar, and D. S. Nolan, 2019: The outflowrainband relationship induced by environmental flow around tropical cyclones. J. Atmos. Sci., 76, 1845-1863, https://doi.org/ 10.1175/JAS-D-18-0208.1.

Dolling, K. P., and G. M. Barnes, 2012: The creation of a high equivalent potential temperature reservoir in Tropical Storm Humberto (2001) and its possible role in storm deepening. Mon. Wea. Rev., 140, 492-505, https://doi.org/10.1175/MWR-D-11-00068.1.

Dudhia, J., 1989: Numerical study of convection observed during the Winter Monsoon Experiment using a mesoscale two-dimensional model. J. Atmos. Sci., 46, 3077-3107, https://doi.org/10.1175/15200469(1989)046<3077:NSOCOD>2.0.CO;2.

Dunion, J. P., 2011: Rewriting the climatology of the tropical North Atlantic and Caribbean Sea atmosphere. J. Climate, 24, 893 908, https://doi.org/10.1175/2010JCLI3496.1.

— C. D. Thorncroft, and C. S. Velden, 2014: The tropical cyclone diurnal cycle of mature hurricanes. Mon. Wea. Rev., 142 , 3900-3919, https://doi.org/10.1175/MWR-D-13-00191.1.

Emanuel, K. A., 1994: Atmospheric Convection. Oxford University Press, $580 \mathrm{pp}$.

- and F. Zhang, 2017: The role of inner-core moisture in tropical cyclone predictability and practical forecast skill. J. Atmos. Sci., 74, 2315-2324, https://doi.org/10.1175/JAS-D-17-0008.1.

Finocchio, P. M., S. J. Majumdar, D. S. Nolan, and M. Iskandarani, 2016: Idealized tropical cyclone responses to the height and depth of environmental vertical wind shear. Mon. Wea. Rev., 144, 2155-2175, https://doi.org/10.1175/MWR-D-15-0320.1.

Fovell, R. G., K. L. Corbosiero, A. Seifert, and K.-N. Liou, 2010: Impact of cloud-radiative processes on hurricane track.
Geophys. Res. Lett., 37, L07808, https://doi.org/10.1029/ 2010GL042691.

, Y. P. Bu, K. L. Corbosiero, W.-w. Tung, Y. Cao, H.-C. Kuo, L.-h. Hsu, and H. Su, 2016: Influence of cloud microphysics and radiation on tropical cyclone structure and motion. Multiscale Convection-Coupled Systems in the Tropics: A Tribute to Dr. Michio Yanai, Meteor. Monogr., No. 56, Amer. Meteor. Soc., https://doi.org/10.1175/AMSMONOGRAPHSD-15-0006.1.

Frank, W. M., 1982: Large-scale characteristics of tropical cyclones. Mon. Wea. Rev., 110, 572-586, https://doi.org/10.1175/15200493(1982)110<0572:LSCOTC $>2.0$.CO;2.

, 1984: A composite analysis of the core of a mature hurricane. Mon. Wea. Rev., 112, 2401-2420, https://doi.org/10.1175/15200493(1984)112<2401:ACAOTC > 2.0.CO;2.

— tropical cyclone structure. Mon. Wea. Rev., 127, 2044-2061, https:// doi.org/10.1175/1520-0493(1999)127<2044:EOEFUT>2.0.CO;2.

— and _ 2001: Effects of vertical wind shear on the intensity and structure of numerically simulated hurricanes. Mon. Wea. Rev., 129, 2249-2269, https://doi.org/10.1175/1520-0493(2001) 129<2249:EOVWSO > 2.0.CO;2.

Ge, X., T. Li, and M. Peng, 2013: Effects of vertical shears and midlevel dry air on tropical cyclone developments. J. Atmos. Sci., 70, 3859-3875, https://doi.org/10.1175/JAS-D-13-066.1.

Gilmore, M. S., and L. J. Wicker, 1998: The influence of midtropospheric dryness on supercell morphology and evolution. Mon. Wea. Rev., 126, 943-958, https://doi.org/10.1175/15200493(1998)126<0943:TIOMDO>2.0.CO;2.

Hong, S.-Y., J. Dudhia, and S.-H. Chen, 2004: A revised approach to ice microphysical processes for the bulk parameterization of clouds and precipitation. Mon. Wea. Rev., 132, 103-120, https:// doi.org/10.1175/1520-0493(2004)132<0103:ARATIM >2.0.CO;2.

_, Y. Noh, and J. Dudhia, 2006: A new vertical diffusion package with an explicit treatment of entrainment processes. Mon. Wea. Rev., 134, 2318-2341, https://doi.org/10.1175/ MWR3199.1.

Houze, R. A., Jr., 2010: Clouds in tropical cyclones. Mon. Wea. Rev., 138, 293-344, https://doi.org/10.1175/2009MWR2989.1.

Iacono, M. J., J. S. Delamere, E. J. Mlawer, M. W. Shephard, S. A. Clough, and W. D. Collins, 2008: Radiative forcing by longlived greenhouse gases: Calculations with the AER radiative transfer models. J. Geophys. Res., 113, D13103, https://doi.org/ 10.1029/2008JD009944.

Judt, F., S. S. Chen, and J. Berner, 2016: Predictability of tropical cyclone intensity: Scale-dependent forecast error growth in high-resolution stochastic kinetic-energy backscatter ensembles. Quart. J. Roy. Meteor. Soc., 142, 43-57, https://doi.org/ 10.1002/qj.2626.

Kessler, E., 1969: On the Distribution and Continuity of Water Substance in Atmospheric Circulations. Meteor. Monogr., No. 10, Amer. Meteor. Soc., 84 pp., https://doi.org/10.1007/978-1935704-36-2_1.

Kwon, Y. C., and W. M. Frank, 2008: Dynamic instabilities of simulated hurricane-like vortices and their impacts on the core structure of hurricanes. Part II: Moist experiments. J. Atmos. Sci., 65, 106-122, https://doi.org/10.1175/ 2007JAS2132.1.

Lim, K.-S. S., and S.-Y. Hong, 2010: Development of an effective double-moment cloud microphysics scheme with prognostic cloud condensation nuclei $(\mathrm{CCN})$ for weather and climate models. Mon. Wea. Rev., 138, 1587-1612, https://doi.org/ 10.1175/2009MWR2968.1. 
McBride, J. L., and R. Zehr, 1981: Observational analysis of tropical cyclone formation. Part II: Comparison of nondeveloping versus developing systems. J. Atmos. Sci., 38, 1132-1151, https://doi.org/10.1175/1520-0469(1981)038<1132: OAOTCF $>2.0 . \mathrm{CO} ; 2$.

Melhauser, C., and F. Zhang, 2014: Diurnal radiation cycle impact on the pregenesis environment of Hurricane Karl (2010). J. Atmos. Sci., 71, 1241-1259, https://doi.org/10.1175/JAS-D13-0116.1.

Miyamoto, Y., and D. S. Nolan, 2018: Structural changes preceding rapid intensification in tropical cyclones as shown in a large ensemble of idealized simulations. J. Atmos. Sci., 75, 555-569, https://doi.org/10.1175/JAS-D-17-0177.1.

Molinari, J., D. Vollaro, and K. L. Corbosiero, 2004: Tropical cyclone formation in a sheared environment: A case study. J. Atmos. Sci., 61, 2493-2509, https://doi.org/10.1175/ JAS3291.1.

—, D. M. Romps, D. Vollaro, and L. Nguyen, 2012: CAPE in tropical cyclones. J. Atmos. Sci., 69, 2452-2463, https://doi.org/ 10.1175/JAS-D-11-0254.1.

— J. Jrank, and D. Vollaro, 2013: Convective bursts, downdraft cooling, and boundary layer recovery in a sheared tropical storm. Mon. Wea. Rev., 141, 1048-1060, https:// doi.org/10.1175/MWR-D-12-00135.1.

Moon, Y., and D. S. Nolan, 2010: Do gravity waves transport angular momentum away from tropical cyclones? J. Atmos. Sci., 67, 117-135, https://doi.org/10.1175/2009JAS3088.1.

Mrowiec, A. A., O. M. Pauluis, and F. Zhang, 2016: Isentropic analysis of a simulated hurricane. J. Atmos. Sci., 73, 18571870, https://doi.org/10.1175/JAS-D-15-0063.1.

Munsell, E. B., F. Zhang, J. A. Sippel, S. A. Braun, and Y. Weng, 2017: Dynamics and predictability of the intensification of Hurricane Edouard (2014). J. Atmos. Sci., 74, 573-595, https:// doi.org/10.1175/JAS-D-16-0018.1.

Murthy, V. S., and W. R. Boos, 2018: Role of surface enthalpy fluxes in idealized simulations of tropical depression spinup. J. Atmos. Sci., 75, 1811-1831, https://doi.org/10.1175/JAS-D17-0119.1.

Nguyen, L. T., and J. Molinari, 2012: Rapid intensification of a sheared, fast-moving hurricane over the Gulf Stream. Mon. Wea. Rev., 140, 3361-3378, https://doi.org/10.1175/MWR-D11-00293.1.

— , R. F. Rogers, and P. D. Reasor, 2017: Thermodynamic and kinematic influences on precipitation symmetry in sheared tropical cyclones: Bertha and Cristobal (2014). Mon. Wea. Rev., 145, 4423-4446, https://doi.org/10.1175/MWR-D-17-0073.1.

Nicholls, M. E., 2015: An investigation of how radiation may cause accelerated rates of tropical cyclogenesis and diurnal cycles of convective activity. Atmos. Chem. Phys., 15, 9003-9029, https://doi.org/10.5194/acp-15-9003-2015.

Nolan, D. S., 2011: Evaluating environmental favorableness for tropical cyclone development with the method of pointdownscaling. J. Adv. Model. Earth Syst., 3, M08001, https:// doi.org/10.1029/2011MS000063.

— , and E. D. Rappin, 2008: Increased sensitivity of tropical cyclogenesis to wind shear in higher SST environments. Geophys. Res. Lett., 35, L14805, https://doi.org/10.1029/2008GL034147.

Nugent, A. D., and R. Rios-Berrios, 2018: Factors leading to extreme precipitation on Dominica from Tropical Storm Erika (2015). Mon. Wea. Rev., 146, 525-541, https://doi.org/10.1175/ MWR-D-17-0242.1.

Onderlinde, M. J., and D. S. Nolan, 2014: Environmental helicity and its effects on development and intensification of tropical cyclones. J. Atmos. Sci., 71, 4308-4320, https://doi.org/10.1175/ JAS-D-14-0085.1.

—, and —, 2016: Tropical cyclone-relative environmental helicity and the pathways to intensification in shear. J. Atmos. Sci., 73, 869-890, https://doi.org/10.1175/JAS-D-15-0261.1.

Pauluis, O. M., and A. A. Mrowiec, 2013: Isentropic analysis of convective motions. J. Atmos. Sci., 70, 3673-3688, https:// doi.org/10.1175/JAS-D-12-0205.1.

—_, and F. Zhang, 2017: Reconstruction of thermodynamic cycles in a high-resolution simulation of a hurricane. J. Atmos. Sci., 74, 3367-3381, https://doi.org/10.1175/JASD-16-0353.1.

Rappin, E. D., and D. S. Nolan, 2012: The effect of vertical shear orientation on tropical cyclogenesis. Quart. J. Roy. Meteor. Soc., 138, 1035-1054, https://doi.org/10.1002/qj.977.

Reasor, P. D., M. T. Montgomery, and L. D. Grasso, 2004: A new look at the problem of tropical cyclones in vertical shear flow: Vortex resiliency. J. Atmos. Sci., 61, 3-22, https://doi.org/ 10.1175/1520-0469(2004)061<0003:ANLATP>2.0.CO;2.

Riemer, M., and M. T. Montgomery, 2011: Simple kinematic models for the environmental interaction of tropical cyclones in vertical wind shear. Atmos. Chem. Phys., 11, 9395-9414, https://doi.org/10.5194/acp-11-9395-2011.

— , and F. Laliberté, 2015: Secondary circulation of tropical cyclones in vertical wind shear: Lagrangian diagnostic and pathways of environmental interaction. J. Atmos. Sci., 72, 3517-3536, https://doi.org/10.1175/JAS-D-14-0350.1.

, M. T. Montgomery, and M. E. Nicholls, 2010: A new paradigm for intensity modification of tropical cyclones: Thermodynamic impact of vertical wind shear on the inflow layer. Atmos. Chem. Phys., 10, 3163-3188, https://doi.org/10.5194/acp-10-3163-2010.

, — , and — 2013: Further examination of the thermodynamic modification of the inflow layer of tropical cyclones by vertical wind shear. Atmos. Chem. Phys., 13, 327-346, https://doi.org/10.5194/acp-13-327-2013.

Rios-Berrios, R., and R. D. Torn, 2017: Climatological analysis of tropical cyclone intensity changes under moderate vertical wind shear. Mon. Wea. Rev., 145, 1717-1738, https://doi.org/ 10.1175/MWR-D-16-0350.1.

,-- , and C. A. Davis, 2016a: An ensemble approach to investigate tropical cyclone intensification in sheared environments. Part I: Katia (2011). J. Atmos. Sci., 73, 71-93, https:// doi.org/10.1175/JAS-D-15-0052.1.

,$- \ldots$, and ——, 2016b: An ensemble approach to investigate tropical cyclone intensification in sheared environments. Part II: Ophelia (2011). J. Atmos. Sci., 73, 1555-1575, https:// doi.org/10.1175/JAS-D-15-0245.1.

— C. A. Davis, and R. D. Torn, 2018: A hypothesis for the intensification of tropical cyclones under moderate vertical wind shear. J. Atmos. Sci., 75, 4149-4173, https://doi.org/10.1175/ JAS-D-18-0070.1.

Rogers, R., 2010: Convective-scale structure and evolution during a high-resolution simulation of tropical cyclone rapid intensification. J. Atmos. Sci., 67, 44-70, https://doi.org/ 10.1175/2009JAS3122.1.

_ - S. Lorsolo, P. Reasor, J. Gamache, and F. Marks, 2012: Multiscale analysis of tropical cyclone kinematic structure from airborne Doppler radar composites. Mon. Wea. Rev., 140, 77-99, https://doi.org/10.1175/MWR-D-10-05075.1.

Rotunno, R., and J. Klemp, 1985: On the rotation and propagation of simulated supercell thunderstorms. J. Atmos. Sci., $\mathbf{4 2}$, 271-292, https://doi.org/10.1175/1520-0469(1985)042<0271: OTRAPO $>2.0 . \mathrm{CO} ; 2$. 
Ryglicki, D. R., J. H. Cossuth, D. Hodyss, and J. D. Doyle, 2018: The unexpected rapid intensification of tropical cyclones in moderate vertical wind shear. Part I: Overview and observations. Mon. Wea. Rev., 146, 3773-3800, https://doi.org/10.1175/ MWR-D-18-0020.1.

— J. D. Doyle, D. Hodyss, J. H. Cossuth, Y. Jin, K. C. Viner, and J. M. Schmidt, 2019: The unexpected rapid intensification of tropical cyclones in moderate vertical wind shear. Part III: Outflow-environment interaction. Mon. Wea. Rev., 147, 2919 2940, https://doi.org/10.1175/MWR-D-18-0370.1.

Schecter, D. A., M. T. Montgomery, and P. D. Reasor, 2002: A theory for the vertical alignment of a quasigeostrophic vortex. J. Atmos. Sci., 59, 150-168, https://doi.org/10.1175/ 1520-0469(2002)059<0150:ATFTVA > 2.0.CO;2.

Skamarock, W. C., and Coauthors, 2008: A description of the Advanced Research WRF version 3. NCAR Tech. Note NCAR.TN-475+STR, 119 pp., https://doi.org/10.5065/ D68S4MVH.

Tang, B., and K. Emanuel, 2010: Midlevel ventilation's constraint on tropical cyclone intensity. J. Atmos. Sci., 67, 1817-1830, https://doi.org/10.1175/2010JAS3318.1.

$\longrightarrow$, and - 2012: Sensitivity of tropical cyclone intensity to ventilation in an axisymmetric model. J. Atmos. Sci., 69, 2394 2413, https://doi.org/10.1175/JAS-D-11-0232.1.

Tao, D., and F. Zhang, 2014: Effect of environmental shear, seasurface temperature, and ambient moisture on the formation and predictability of tropical cyclones: An ensemble-mean perspective. J. Adv. Model. Earth Syst., 6, 384-404, https:// doi.org/10.1002/2014MS000314.

- , and —, 2015: Effects of vertical wind shear on the predictability of tropical cyclones: Practical versus intrinsic limit. J. Adv. Model. Earth Syst., 7, 1534-1553, https://doi.org/ 10.1002/2015MS000474.

Thompson, G., P. R. Field, R. M. Rasmussen, and W. D. Hall, 2008: Explicit forecasts of winter precipitation using an improved bulk microphysics scheme. Part II: Implementation of a new snow parameterization. Mon. Wea. Rev., 136, 5095-5115, https://doi.org/10.1175/2008MWR2387.1.

Van Sang, N., R. K. Smith, and M. T. Montgomery, 2008: Tropicalcyclone intensification and predictability in three dimensions. Quart. J. Roy. Meteor. Soc., 134, 563-582, https://doi.org/ 10.1002/qj.235.

Wing, A. A., S. J. Camargo, and A. H. Sobel, 2016: Role of radiative-convective feedbacks in spontaneous tropical cyclogenesis in idealized numerical simulations. J. Atmos. Sci., 73, 2633-2642, https://doi.org/10.1175/JAS-D-150380.1.

Zhang, F., and D. Tao, 2013: Effects of vertical wind shear on the predictability of tropical cyclones. J. Atmos. Sci., 70, 975-983, https://doi.org/10.1175/JAS-D-12-0133.1.

Zhou, W., 2015: The impact of vertical shear on the sensitivity of tropical cyclogenesis to environmental rotation and thermodynamic state. J. Adv. Model. Earth Syst., 7, 1872-1884, https:// doi.org/10.1002/2015MS000543. 